\title{
Action of a RAP1 carboxy-terminal silencing domain reveals an underlying competition between $H M R$ and telomeres in yeast
}

\author{
Stephen W. Buck and David Shore ${ }^{1}$ \\ Department of Microbiology, College of Physicians and Surgeons of Columbia University, New York, New York 10032 USA
}

RAP1 is a sequence-specific DNA-binding protein in yeast that can either repress or activate transcription. Previous studies have demonstrated a direct role for RAP1 in silencing at $H M$ mating-type loci and telomeres. Here, we show that a small carboxy-terminal domain of RAP1 is sufficient to establish repression when fused to the GAL4 DNA-binding domain $\left(\mathrm{G}_{\mathrm{BD}}\right)$ and targeted to mutated $H M R$ silencers containing GAL4 DNA-binding sites. Silencing by $\mathrm{G}_{\mathrm{BD}} / \mathrm{RAP1}$ hybrids, like normal silencing at $H M R$, requires the trans-acting factors SIR2, SIR3, and SIR4. However, $\mathrm{G}_{\mathrm{BD}}$ /RAP1-mediated silencing is independent of SIR1, whose product is normally required for the establishment of repression at $H M R$. Targeted silencing also displays an unusual response to silencing-defective $\operatorname{rap} 1^{s}$ mutations. The incorporation of a $\operatorname{rap} 1^{s}$ missense mutation into $\mathrm{G}_{\mathrm{BD}}$ /RAP1 hybrids can improve targeted silencing, yet wild-type $\mathrm{G}_{\mathrm{BD}}$ /RAP1 hybrids fail to establish repression in strains in which the endogenous RAP1 locus carries a rap $1^{s}$ mutation. In addition, we find that

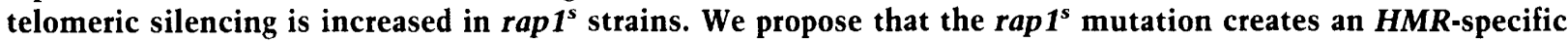
silencing defect by shifting a balance between silencing at HMR and telomeres in favor of telomeric silencing. This balance is regulated by telomere length and by interactions between the RAP1 carboxyl terminus and both RIF1 and SIR4 proteins. In support of this model, we show that abnormally long telomeres antagonize silencing at $H M R$ and a rap $1^{\text {s }}$ hybrid protein displays a strengthened interaction with SIR4 in a two-hybrid assay.

[Key Words: Transcriptional silencing; RAP1; silencer; telomere; mating type]

Received May 10, 1994; revised version accepted December 15, 1994.

Mating-type genes in the yeast Saccharomyces cerevisiae are subject to a position-effect repression phenomenon called silencing (Klar et al. 1981; Nasmyth et al. 1981; Abraham et al. 1984; Feldman et al. 1984; Brand et al. 1985). When present at the MAT locus near the centromere of chromosome III, these genes (a or $\alpha$ ) are expressed and regulate cell type (a or $\alpha$ haploid or nonmating a $/ \alpha$ diploid types!. Two other copies of mating-type information are present near the telomeres of chromosome III at loci called $H M L$ and $H M R$. Although the $H M$ loci contain complete structural gene and promoter sequences, they are not normally transcribed, because of the action of flanking regulatory elements called silencers and a number of trans-acting factors (for review, see Laurenson and Rine 1992).

Silencing at the $H M R$ locus (which usually contains a information) requires a flanking silencer element called $H M R-E$. This silencer is comprised of three partially redundant regulatory elements, called A, E, and B (Brand et

${ }^{1}$ Corresponding author. al. 1987; Kimmerly et al. 1988). The A element is an autonomously replicating sequence (ARS) consensus sequence (ACS) recognized by a set of six proteins called the origin recognition complex (ORC) (Bell and Stillman 1992; Diffley and Cocker 1992). Temperature-sensitive mutations in the ORC2 protein confer a silencing defect at the permissive temperature, demonstrating a role for the ORC in transcriptional silencing (Bell et al. 1993; Foss et al. 1993; Micklem et al. 1993). The E and B sites are binding sites for two abundant and essential regulatory proteins, RAPl and ABF1, respectively (Shore and Nasmyth 1987; Shore et al. 1987; Buchman et al. 1988a,b; Diffley and Stillman 1989). A role for RAP1 in silencing has been demonstrated by the isolation of mutations in the protein that result in derepression of either $H M L$ or HMR (Kurtz and Shore 1991; Sussel and Shore 1991; Kyrion et al. 1993). In contrast to ORC and RAP1, there is as yet no direct evidence for the role of $A B F 1$ in silencing. An intriguing feature of both RAP1 and ABF1 is that they also bind to the promoters of a large number of genes, where they often function as transcriptional 
activators (Shore and Nasmyth 1987; Buchman et al. 1988b).

Transcriptional silencing at $H M$ loci also requires a number of other trans-acting factors in addition to the known silencer binding proteins. These include the products of the four SIR (silent information regulator) genes (Haber and George 1979; Klar et al. 1979'; Rine et al. 1979; Shore et al. 1984; Ivy et al. 1986; Rine and Herskowitz 1987; Stone et al. 1991). The SIR proteins are presumed to be involved in either the establishment or maintenance of an altered chromatin structure at $H M$ loci and telomeres, although the precise role of these proteins in silencing is at present unclear. Important insights into the nature of silencing have come from studies of the SIR1 gene. Pillus and Rine (1989) showed that mutation of SIR 1 creates a different phenotype than mutation of any of the other three SIR genes. In cells mutant for either $S I R 2$, SIR3, or SIR4, silencing cannot be maintained, and these cells are uniformly derepressed. In contrast, repression at $H M L$ is only destabilized in $\operatorname{sir} 1 \mathrm{mu}$ tant cells, leading to the production of two populations of cells (repressed and derepressed) within a clonal culture. It was proposed, therefore, that SIR I plays a specific role in the establishment of silencing. This hypothesis is supported by recent experiments that indicate that SIRI acts at the HMR-E silencer (Chien et al. 1993).

Telomeres in yeast can also act as silencer elements, repressing the expression of genes placed in their vicinity (Gottschling et al. 1990). Telomeric silencing, also known as telomere position effect (TPE), probably occurs by a process similar to silencing at the $H M$ loci because it requires the function of three of the four $S I R$ genes (SIR2, SIR3, SIR4). TPE differs from HM silencing, however, in that it is inherently unstable and unaffected by mutation of SIR1 (Aparicio et al. 1991). The instability of TPE can be explained by an inability of telomeres to utilize the SIR1 establishment function /Chien et al. 1993). At present, the only known sequence-specific DNA-binding protein that mediates TPE is RAP1 (Kyrion et al. 1993), whose binding sites occur often within the terminal $\mathrm{C}_{1-3} \mathrm{~A}$ repeats at telomeres (Longtine et al. 1989; Gilson et al. 1993). It appears, therefore, that TPE is not brought about by discrete silencer elements analogous to those at HM loci but is instead mediated by long poly $\left(\mathrm{C}_{1-3} \mathrm{~A}\right)$ tracts $(\sim 300 \mathrm{bp})$ to which multiple copies of RAPl are bound.

Mutational analysis has indicated that the carboxyl terminus of RAPl is critical for both $H M$ silencing and TPE (Sussel and Shore 1991; Kyrion et al. 1993). For example, missense mutations in the RAPl carboxyl terminus, referred to as rap $1^{s}$ alleles, result in derepression of $H M R$ when the $H M R-E$ silencer is weakened by mutation of the ACS (hmr $\Delta A$ ) (Sussel and Shore 1991). The rap $1^{s}$ mutations also result in elongation of the poly $/ \mathrm{C}_{1-}$ ${ }_{3} \mathrm{~A}$ ) tracts at telomeres by as much as $50 \%$. A detailed characterization of the rap $1^{s}$ mutants has indicated that their defect may be in the establishment of repression at $H M R$, rather than its maintenance (Sussel et al. 1993). Truncations of the carboxyl terminus of RAPl lead to a complete loss of TPE and HML silencing but fully dere- press $H M R$ only when the $H M R-E$ silencer is mutated (hmr $\Delta A$ ) (Kyrion et al. 1993; Moretti et al. 1994). Severe RAP1 truncation alleles $\left(r a p 1^{t}\right)$ display dramatic increases in telomere tract length (>10-fold). However, this alteration of telomere structure does not explain the loss of TPE in rap $1^{t}$ mutants. In fact, when elongated telomeres are inherited by RAP1 wild-type spores after a cross with a rap $1^{t}$ mutant, silencing at these telomeres is found to be stronger than silencing at normal-length telomeres (Kyrion et al. 1993).

Experiments employing GAL4 DNA-binding domain $\left(\mathrm{G}_{\mathrm{BD}}\right) / \mathrm{RAPl}$ hybrid proteins have provided further insights into the function of the RAP1 carboxyl terminus, indicating that it plays a role in both silencing and transcriptional activation (Hardy et al. 1992a). $\mathrm{G}_{\mathrm{BD}} / \mathrm{RAP1}$ hybrids containing residues $630-695$ of RAPl function as transcriptional activators when targeted to a $G A L 1-$ $1 a c Z$ reporter gene, suggesting that this region of RAPl may function as a transcriptional activation domain in the native protein. On the other hand, hybrids containing sequences from residue 678 to the end of the protein (amino acid 827) interfere with silencing when overexpressed, suggesting that this carboxy-terminal domain of RAPl may normally play a role in repression. This dominant-negative effect on silencing produced by overexpression suggests that the RAPl carboxyl terminus mediates its effects at silencers and telomeres through interactions with other proteins. One such protein, RIFl, was identified in a two-hybrid screen (Hardy et al. 1992b). rif1 mutants, like rap $1^{\text {s }}$ mutants, display a $h m r \Delta A$-specific silencing defect. In addition, rapls proteins are defective in RIFl binding, suggesting that one function of RAPl at HMR is to recruit RIF1 to the silencer.

Here, we have extended our studies of the role of the RAP1 carboxyl terminus in silencing at $H M R$. Using $\mathrm{G}_{\mathrm{BD}} / \mathrm{RAPl}$ hybrid proteins, we have identified a small carboxy-terminal domain of RAPl that is sufficient to establish repression when targeted to an $H M R-E$ silencer deleted for all three of the normal regulatory sites $(A, E$, and $B \mid$. Targeted silencing by $G_{B D} / R A P 1$ hybrids requires the function of SIR2, SIR3, and SIR4 but differs from normal silencing at $H M R$ in that it is independent of SIR1 function. Surprisingly, $\mathrm{G}_{\mathrm{BD}} / \mathrm{rapl}^{\text {s }}$ hybrids display no defect in targeted silencing, whereas a chromosomal rap $1^{s}$ mutation abolishes the ability of $\mathrm{G}_{\mathrm{BD}} / \mathrm{RAPl}$ (but not $\mathrm{G}_{\mathrm{BD}} / \mathrm{rapl}^{\text {s }}$ / hybrids to repress at $H M R$. We explain these results in terms of a model in which the $H M R$ silencer and telomeres compete for limiting silencing factors.

\section{Results}

To investigate the transcriptional silencing functions of RAP1 in more detail, we developed a system in which RAP1 hybrid proteins substitute for endogenous silencer binding factors at the HMR-E silencer (see Fig. 1). The hybrid proteins consist of carboxy-terminal sequences of RAPl fused to the $\mathrm{G}_{\mathrm{BD}}$ (Hardy et al. 1992a) and are expressed from the RAP1 promoter. To assay the activity of 

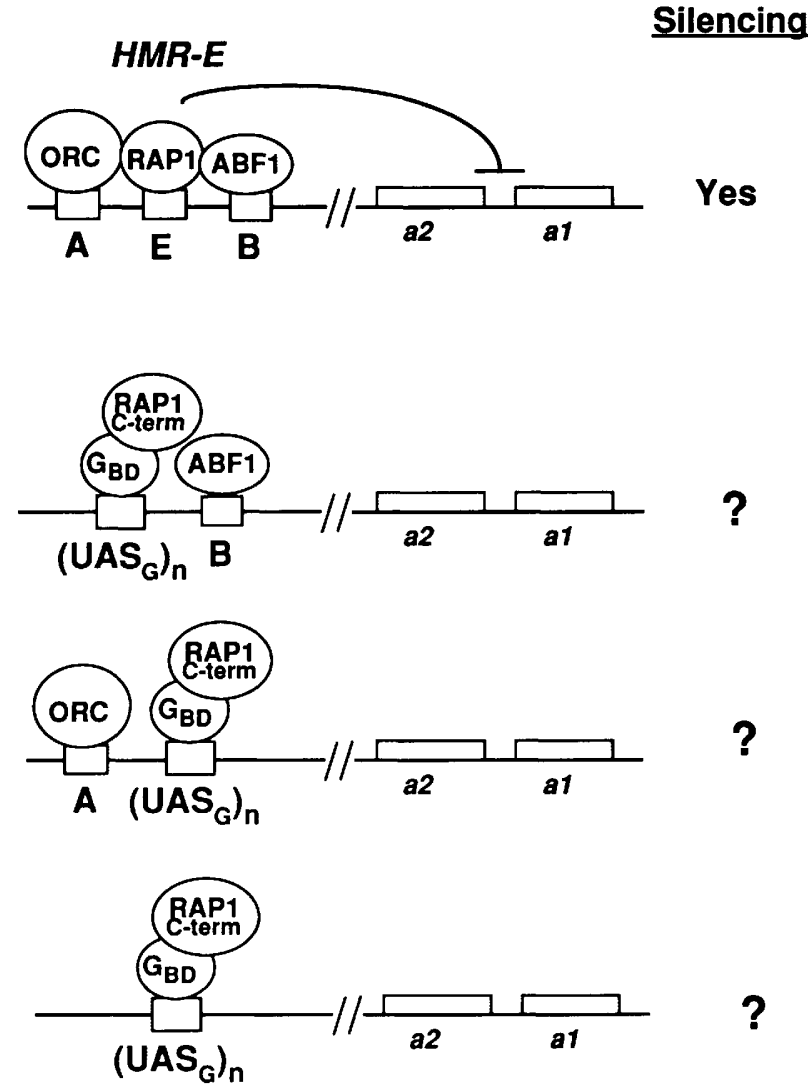

?

Figure 1. Schematic representation of the targeted silencing strategy employed in these studies. The wild-type HMR-E silencer is shown on the top line. As noted in the text, both $\Delta \mathrm{A}$ and $\Delta \mathrm{B}$ silencers are completely functional, whereas the doublemutant silencers $\triangle \mathrm{A} \Delta \mathrm{E}$ and $\Delta \mathrm{E} \Delta \mathrm{B}$ and the triple-mutant silencer $(\triangle \mathrm{A} \Delta \mathrm{E} \Delta \mathrm{B})$ are derepressed.

these hybrids, we used three types of strains containing GAL4-binding sites $\left(\mathrm{UAS}_{\mathrm{G}}\right)$ inserted at mutated silencers (see Materials and methods; Table 1). In the first two sets of strains, the HMR-E silencer is deleted for the RAP1 binding site (E) and either the ORC-binding site (A) or the ABFl-binding site (B). These silencers are referred to as $\triangle \mathrm{A} \Delta \mathrm{E}::\left(\mathrm{UAS}_{\mathrm{G}}\right)_{n}$ and $\triangle \mathrm{E} \Delta \mathrm{B}::\left(\mathrm{UAS}_{\mathrm{G}}\right)_{n}$, respectively, where $n$ indicates the number of GAL4-binding sites inserted within the silencer deletion. In the third type, $\Delta \mathrm{A} \Delta \mathrm{E} \Delta \mathrm{B}:\left(\mathrm{UAS}_{\mathrm{G}}\right)_{n}$, all three known silencer regulatory sites have been deleted and are replaced by binding sites for the GAL4 protein. All three of these mutated silencers are completely defective in repression (Brand et al. 1987; Kimmerly et al. 1988). To assay the function of $\mathrm{G}_{\mathrm{BD}} / \mathrm{RAP1}$ hybrids in these strains, hybrid gene constructs are either integrated in single copy at the HIS 3 locus or expressed from low-copy-number centromere (CEN) plasmids. All relevant strains contain a gal4::LEU2 gene disruption to avoid competition by native GAL4 for binding to the $\mathrm{UAS}_{\mathrm{G}}$-containing silencers.

$G_{B D} / R A P 1$ hybrids restore repression when targeted to mutated HMR-E silencers

We first tested the ability of $G_{B D} / R A P 1$ hybrids to re- press the al gene normally found at the $H M R$ locus. A CEN plasmid expressing a $G_{B D} / R A P 1$ hybrid containing the carboxy-terminal 175 amino acids of RAPl $\left[\mathrm{G}_{\mathrm{BD}} /\right.$ RAP1 $(653-827)]$ or a control plasmid expressing $G_{B D}$ alone were introduced into strains with or without $\mathrm{UAS}_{\mathrm{G}}$ sites at the HMR-E silencer. We first assayed for transcriptional silencing directly by measuring steadystate al mRNA levels in these strains. As shown in Figure 2, the expression of $\mathrm{G}_{\mathrm{BD}} / \mathrm{RAP1}(653-827)$ resulted in either a reduction or a complete loss of detectable a1 mRNA with all three types of $\mathrm{UAS}_{\mathrm{G}}$-containing silencers. The $G_{B D}$ control plasmid failed to confer repression in all cases. Control strains lacking $\mathrm{UAS}_{\mathrm{G}}$ sites at $H M R$ also remained derepressed in the presence of $\mathrm{G}_{\mathrm{BD}} /$ RAP1(653-827), demonstrating that the site of action for the hybrid protein is the mutated silencer. In addition, we noticed that the level of repression is influenced by the number of $\mathrm{UAS}_{\mathrm{G}}$ sites at the silencer. For example, a single site in the $\triangle \mathrm{A} \Delta \mathrm{E}$ silencer gave partial repression, whereas multiple tandem sites cloned into this deletion resulted in full repression. Although the $\mathrm{A}$ and $\mathrm{B}$ sites at $H M R-E$ appear to increase the level of repression by $\mathrm{G}_{\mathrm{BD}} /$ RAP1(653-827), they are not absolutely required, because repression can occur in their absence. However, full repression at the $\triangle \mathrm{A} \Delta \mathrm{E} \Delta \mathrm{B}$ silencer requires more $\mathrm{UAS}_{\mathrm{G}}$ sites than are needed at silencers containing either A or B. The triple-deletion silencer gives only partial repression with three copies of $\mathrm{UAS}_{\mathrm{G}}$. Full repression is only achieved when four copies are present. These results closely parallel mutational analyses of the HMR-E silencer element (Brand et al. 1987; Kimmerly et al. 1988 ) that demonstrated that full repression required the E site (the RAPl binding site) plus either the A or B sites. The results from the RNA blot were confirmed by measuring the mating efficiency of these strains, a biological assay for silencing. We found a strict correlation between the decrease in al mRNA levels in these strains and their ability to mate with a MATa haploid tester strain /data not shown).

To further characterize silencing mediated by $\mathrm{G}_{\mathrm{BD}} /$ RAP1(653-827), we examined its effect in strains containing a TRP1 reporter gene at $H M R$ in place of the normal al and a2 genes. In these strains repression is reflected by a reduction in the ability to form colonies on medium lacking tryptophan. Previous studies have shown that the TRP1 reporter can provide an accurate and sensitive assay for silencing (Sussel and Shore 1991). Because this assay measures the properties of individual cells in a culture, it can reveal a loss of repression in a small fraction of cells within a population that might go undetected in an mRNA assay. Figure $3 \mathrm{~A}$ shows the effect of the $\mathrm{G}_{\mathrm{BD}} / \mathrm{RAP} 1(653-827)$ hybrid on TRP1 expression in three different mutant silencer contexts $(\triangle \mathrm{A} \Delta \mathrm{E}$, $\Delta \mathrm{E} \Delta \mathrm{B}$, or $\Delta \mathrm{A} \Delta \mathrm{E} \Delta \mathrm{B}$ ) with or without $\mathrm{UAS}_{\mathrm{G}}$ sites. The hybrid gene in these experiments is integrated in single copy at the HIS 3 locus. In both of the double-mutant silencer strains the ability to form colonies on plates lacking tryptophan is reduced $>10^{3}$-fold by expression of the hybrid protein. Consistent with the results from the HMRa strains, repression of TRP1 was dependent on 
Table 1. Yeast strains

\begin{tabular}{|c|c|c|}
\hline Strain & Genotype $^{a}$ & Source \\
\hline W303-1B & $\begin{array}{l}\text { HML } \alpha M A T \alpha \text { HMRa ade2-1 ura3-1 his3-11,15leu2-3,112 trp1-1 } \\
\quad \text { can1-100 }\end{array}$ & R. Rothstein (pers. comm.) \\
\hline YSB 1 & W303-1B $\underline{\triangle A \Delta E}$ hmr::TRP1 ga14::LEU2 & Chien et al. (1993) \\
\hline YSB2 & YSB1 except $\triangle A \Delta E::\left(U A S_{G}\right)_{3}$ & Chien et al. (1993) \\
\hline YSB4 & YSB1 except $\triangle A \Delta E::(U A S)_{G}$ & Chien et al. (1993) \\
\hline YSB35 & YSB1 except $\underline{\Delta E \Delta B::(U A S})_{3}$ & Chien et al. (1993) \\
\hline YSB44 & W303-1B $\triangle A \overline{\Delta E::\left(U A S_{G}\right)_{1}}$ ga14::LEU2 & this study \\
\hline YSB46 & YSB44 except $\underline{\Delta A \Delta E\left(U A S_{C}\right)_{3}}$ & this study \\
\hline YSB48 & YSB44 except $\left.\underline{\underline{\Delta A E \mid U A S}}{ }_{G}\right)_{4}$ & this study \\
\hline YSB50 & YSB44 except $\left.\underline{\triangle A \Delta E \mid U A S}{ }_{G}\right)_{7}$ & this study \\
\hline YSB54 & YSB44 except $\underline{\Delta A \Delta E(U A S})_{G}$ & this study \\
\hline YSB62 & YSB44 except $\triangle A \Delta E \Delta B\left(U A S{ }_{G}\right)_{3}$ & this study \\
\hline YSB66 & YSB44 except $\left.{ }_{\triangle A \Delta E \Delta B(U A S}\right)_{4}$ & this study \\
\hline YSB68 & YSB44 except $\underline{\Delta A \Delta E}$ & this study \\
\hline YSB70 & YSB44 except $\underline{\Delta E \Delta B}$ & this study \\
\hline YSB72 & YSB44 except $\overline{\triangle A \Delta E} \Delta B$ & this study \\
\hline YDS31 & MATa his1 & K. Nasmyth (pers. comm.) \\
\hline YDS655 & W303-1B except HIS3 & R. Rothstein (pers. comm.) \\
\hline YSB256 & 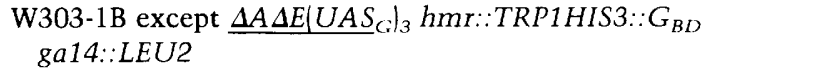 & this study \\
\hline YSB107 & YSB256 except $H I S 3:: G_{B D} / R A P 1(653-827)$ & this study \\
\hline YSB 114 & YSB107 except $\triangle A \Delta E$ hmr::TRP1 & this study \\
\hline YSB 127 & YSB256 except $\overline{\Delta E \Delta B}\left(U A S_{C}\right)_{3} h m r:: T R P 1$ & this study \\
\hline YSB123 & YSB127 except $\overline{G_{B D} / R A P 1}(653-827)$ & this study \\
\hline YSB 140 & YSB 123 except $\underline{\Delta E \Delta B} h m r:: T R P 1$ & this study \\
\hline YSB 103 & YSB107 except $\underline{\triangle A \Delta E \Delta B\left(U A S_{(}\right)_{3} h m r:: T R P 1}$ & this study \\
\hline YSB 102 & YSB103 except $H I S 3:: G_{B 1} / R A P 1(653-827)$ & this study \\
\hline YSB252 & YSB107 except $H I S 3:: G_{B 1} / R A P 1(667-827)$ & this study \\
\hline YSB253 & YSB107 except $H I S 3:: G_{B 1} / R A P I(679-827)$ & this study \\
\hline YSB254 & YSB107 except $H I S 3:: G_{B 1} / R A P 1(702-827)$ & this study \\
\hline YSB255 & YSB107 except $H I S 3:: G_{B I} / R A P 1(653-799)$ & this study \\
\hline YSB257 & YSB107 except HIS3:: $G_{B 1} / R A P 1(562-827)$ & this study \\
\hline YSB258 & YSB107 except $H I S 3:: G_{B l} / R A P 1(588-827)$ & this study \\
\hline YSB259 & YSB107 except $H I S 3:: G_{m l} / R A P 1(618-827)$ & this study \\
\hline YSB260 & YSB107 except HIS3:: $G_{B 1} / R A P 1(630-827)$ & this study \\
\hline YDS702 & W303-1B except $\underline{\Delta A} \operatorname{sir} 1: \because U R A 3$ & this study \\
\hline YSB 160 & YSB2 except $\operatorname{sir} 1: \because U R A 3(\mathrm{RS} 1172)$ & C.-t. Chien and R. Sternglanz (pers. comm.) \\
\hline RS1042 & YSB2 sir2::URA3 & Chien et al. (1993) \\
\hline RS1061 & YBS2 $\operatorname{sir} 3:: U R A 3$ & Chien et al. (1993) \\
\hline RS1067 & YSB2 $\operatorname{sir} 4:: U R A 3 M A T \mathbf{a}$ & Chien et al. (1993) \\
\hline YSB76 & YSB 114 except rap 1-12::URA3 & this study \\
\hline YSB300 & YSB 107 except rif $1:: U R A 3$ & this study \\
\hline YSB302 & YSB 110 except rif $1:: U R A 3$ & this study \\
\hline YSB 110 & YSB114 except $H I S 3:: G_{B I} /$ rap 1-12(653-827) & this study \\
\hline YSB74 & YSB110 except rap1-12::URA3 & this study \\
\hline YSB 116 & YSB114 except HIS3:: $G_{B D} / \operatorname{rap} 1-12(653-827)$ & this study \\
\hline YSB80 & YSB 107 except MATa & this study \\
\hline YSB282 & YSB80 except $H I S 3:: G_{B D} /$ rap1-12(653-827) & this study \\
\hline AJL394-2a & W303-1B except rap1-17 ADE2:URA3:TelVIIL & A. Lustig (pers. comm.) \\
\hline AJL275-2a & AJL394-2a except RAP1 & A. Lustig (1993) \\
\hline AJL440-1c & AJL275-2a except rap1-17 MATa & A. Lustig (pers. comm.) \\
\hline YSB237 & YSB2 except rif $1:: U R A 3$ & this study \\
\hline CTY10-5D & $\begin{array}{l}\text { MATa ade2-1 trp1-901 leu2-3, } 112 \text { his3-200gal4 gal80 } \\
\text { URA3::lexA op-lacZ }\end{array}$ & C.-t. Chien and R. Sternglanz (pers. comm.) \\
\hline YSB215 & $\begin{array}{l}\text { W303-1B except } \underline{\Delta A} \text { hmr::TRP1 adh4::URA3rap } 1:: \text { LEU2 } \\
\quad p(C E N-H I S 3-R A P 1)\end{array}$ & this study \\
\hline YSB216 & YSB215 except $p(C E N-H I S 3-r a p 1-12)$ & this study \\
\hline YSB290 & W303-1B except $\underline{\Delta A} h m r:: T R P 1$ & this study \\
\hline YSB284-7 & YSB107, except derived from $R A P 1 /$ rap $1-17$ diploid & this study \\
\hline YSB288-9 & YSB110, except derived from $R A P 1 /$ rap $1-17$ diploid & this study \\
\hline YSB291-4 & YDS290, except derived from $R A P 1 /$ rap1-17 diploid & this study \\
\hline YSB304 & YSB291, except MATa & this study \\
\hline YSB296 & YDS290, except derived from $R A P 1 / Y S B 293$ diploid & this study \\
\hline YSB297 & YSB290, except derived from YSB293/YSB304 diploid & this study \\
\hline YSB298 & YSB290, except derived from rap1 $1^{t} /$ YSB293 diploid & this study \\
\hline
\end{tabular}

anderlined part of genotype refers to the deletion mutation at the HMR-E silencer. 


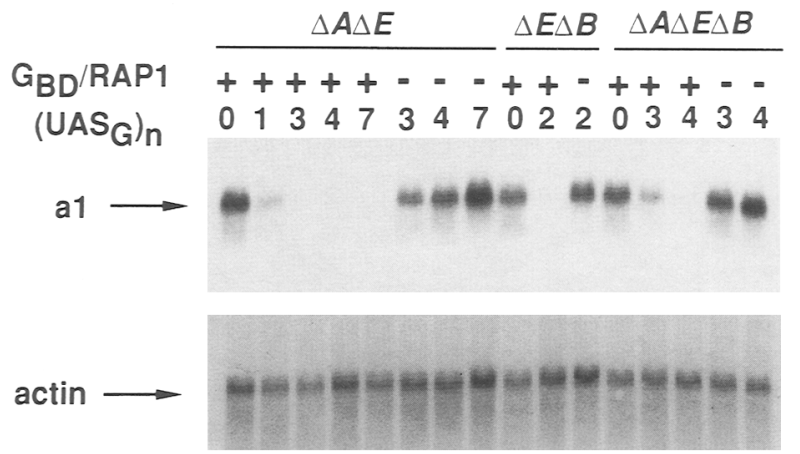

Figure 2. Targeted silencing by the $\mathrm{G}_{\mathrm{BD}} / \mathrm{RAP} 1(653-827)$ hybrid protein at two double-deletion $H M R-E$ silencers $(\triangle \mathrm{A} \Delta \mathrm{E}$ and $\triangle \mathrm{E} \Delta \mathrm{B})$ and the triple-deletion silencer $(\triangle \mathrm{A} \Delta \mathrm{E} \Delta \mathrm{B})$ is GAL4-binding site $\left(\mathrm{UAS}_{\mathrm{G}}\right)$ - and RAP1-dependent. The $H M R$ locus contains the endogenous al gene, whose steady-state expression is measured by Northern blotting. Actin message is shown as a control. The number above each lane indicates the number of UAS $_{\mathrm{G}}$ sites present at the silencer deletion. $(+1$ The presence of the $\mathrm{G}_{\mathrm{BD}} / \mathrm{RAP1}$ plasmid; $(-)$ the presence of a plasmid expressing $\mathrm{G}_{\mathrm{BD}}$ only.

RAPl sequences in the hybrid protein and GAL4-binding sites at the mutant silencer. Unlike the case for the $H M R$ a strain, where partial repression was observed, we did not find evidence for repression of TRP1 by $\mathrm{G}_{\mathrm{B1}}$ / RAP1 $(653-827)$ in a strain with a triple-deletion silencer containing three copies of $\mathrm{UAS}_{\mathrm{G}}$. This could reflect subtle differences in the sensitivities of the two genes (TRP1 and al) to the silencer or a very low threshold of TRP1 expression required for growth on - Trp medium.

$\mathrm{G}_{\mathrm{BD}} / \mathrm{RAPl}$ hybrids were used previously to define a transcriptional activation domain in RAPl that extends from amino acid 630 to 695 (Hardy et al. 1992a). The $\mathrm{G}_{\mathrm{BD}} / \mathrm{RAP1}$ (653-827) hybrid, though it contains part of this region, is incapable of activating transcription. To ask whether RAPl hybrids that can function as activators are also capable of bringing about repression when targeted to $H M R$, we tested a series of larger hybrids with RAPl amino-terminal endpoints at amino acids 630 , 618,588 , and 562 . Constructs expressing these hybrids were integrated at the HIS 3 locus in a strain containing a $\triangle \mathrm{A} \triangle \mathrm{E}::\left(\mathrm{UAS}_{\mathrm{G}}\right)_{3}$ silencer linked to the TRP1 reporter gene. As shown in Figure $3 B$, all four of these $G_{B D} / R A P 1$ activators can act as repressors when targeted to $H M R$. This result indicates that the opposing functions of these hybrids (activation and repression) are regulated by the context of the GAL4-binding sites.

We then mapped the sequences in RAPl required for silencing by the $\mathrm{G}_{\mathrm{BD}} / \mathrm{RAP1}(653-827)$ hybrid. Removal of 14 amino acids from the RAP1 junction to create $\mathrm{G}_{\mathrm{BD}}$ / RAPl(667-827) had no effect on silencing, whereas two larger deletions, $\mathrm{G}_{\mathrm{BD}} / \mathrm{RAP} 1(679-827)$ and $\mathrm{G}_{\mathrm{BD}} /$ RAP1(702-827), showed partial or no activity, respectively (Fig. 3C). We do not yet know whether these hybrids are defective as a result of the loss of sequences required for silencing or because they fail to produce a stable hybrid protein. A small deletion of the carboxyl terminus, $\mathrm{G}_{\mathrm{BD}} / \mathrm{RAPl}(653-799)$ was also completely defective in repression, yet probably produces at least some stable protein because a related LexA/RAP1 hybrid functions as a transcriptional activator (Moretti et al. 1994).

A

Targeted
Protein $\quad$ Silencer

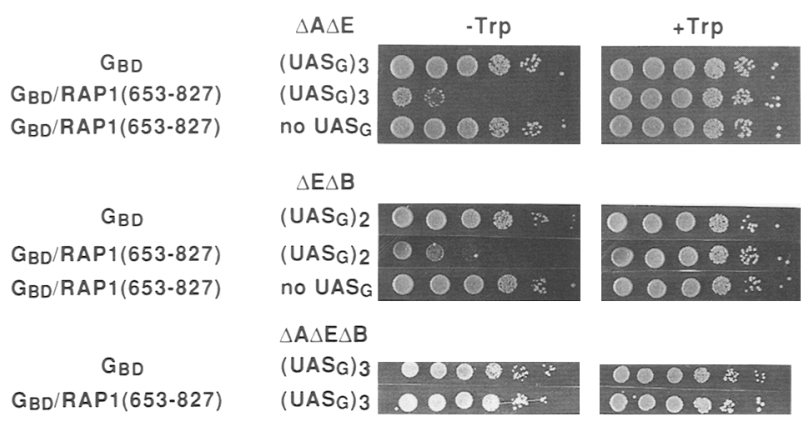

B

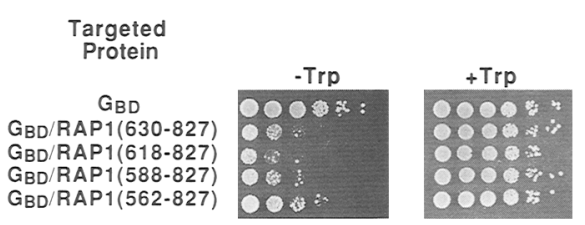

C

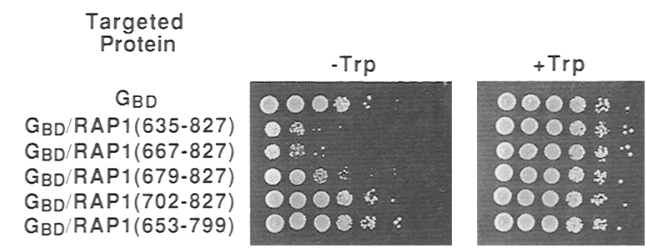

Figure 3. Targeted silencing of an hmr::TRP1 reporter by $\mathrm{G}_{\mathrm{BD}} /$ RAPl hybrid proteins. Silencing is measured by comparing the ability of cells to grow in the absence $(-\operatorname{Trp})$ and presence $(+\operatorname{Trp})$ of tryptophan. Each row consists of spots representing $5-\mu 1$ aliquots from a set of 10 -fold serial dilutions of a liquid culture. $(A)$ Effect of the $\mathrm{G}_{\mathrm{BD}} / \mathrm{RAP} 1(653-827)$ hybrid at $h m r:: T R P 1$ loci with different HMR-E silencer deletions. The $\mathrm{UAS}_{\mathrm{G}}$-containing $\triangle \mathrm{A} \Delta \mathrm{E}$ strains are YSB256 and YSB107 [with $\mathrm{G}_{\mathrm{BD}}$ alone and $\mathrm{G}_{\mathrm{BD}} / \mathrm{RAPl}(653-827)$, respectivelyl, the corresponding $\triangle \mathrm{E} \triangle \mathrm{B}$ strains are YSB127 and YSB123, and the corresponding $\triangle \mathrm{A} \triangle \mathrm{E} \Delta \mathrm{B}$ strains are $\mathrm{YSB} 103$ and $\mathrm{YSB} 102$. The control strains lacking $\mathrm{UAS}_{\mathrm{G}}$ sites at the $\triangle \mathrm{A} \Delta \mathrm{E}$ and $\triangle \mathrm{E} \Delta \mathrm{B}$ silencers are YSB114 and YSB140, respectively. $(B) \mathrm{G}_{\mathrm{BD}} / \mathrm{RAP1}$ hybrids containing a functional RAPl activation domain can repress transcription when targeted to a mutated HMR-E silencer. The strains used in these experiments are YSB256, YSB260, YSB259, YSB258, and YSB257 (top to bottom). (C) Mapping of the aminoand carboxy-terminal boundaries of a RAP1 silencing domain using a series of $\mathrm{G}_{\mathrm{BD}} / \mathrm{RAP1}$ hybrids in strain YSB256, YSB252, YSB253, YSB254, and YSB255 (top to bottom). 
Several missense mutations that abolish the silencing function of the $\mathrm{G}_{\mathrm{BD}} / \mathrm{RAP} 1$ (653-827) hybrid map to the region deleted in this construct, further indicating the importance of the last 28 amino acids for the silencing activity of the hybrid. These mutants will be described elsewhere.

Establishment of silencing by a $G_{B D} / R A P 1$ hybrid is dependent on SIR2, SIR3, and SIR4, but not on SIR1

To determine whether $\mathrm{G}_{\mathrm{BD}} / \mathrm{RAP1}$ (653-827)-mediated silencing resembles normal silencing at $H M R$, we examined its dependency on $S I R$ gene function. A series of derivatives of the $\triangle \mathrm{A} \Delta \mathrm{E}:\left(\mathrm{UAS}_{\mathrm{G}}\right)_{3} h m r:: T R P 1$ reporter strain was constructed in which individual $S I R$ genes were mutated by gene disruption (Chien et al. 1993). These strains were then transformed with a CEN plasmid expressing the $\mathrm{G}_{\mathrm{BD}} / \mathrm{RAPl}(653-827)$ hybrid and tested for silencing. As shown in Figure 4, repression by $\mathrm{G}_{\mathrm{BD}} / \mathrm{RAP1}(653-827)$ is completely lost in sir2, sir3, and sir4 mutant cells. Strikingly, no loss of silencing was detected in a $\operatorname{sir} 1$ mutant. In contrast, silencing dependent on native RAPl, in strains containing a $h m r \Delta A$ silencer, is completely abolished by mutation of SIR1 (Fig. 4 , cf. rows 3 and 4$)$. We conclude from this that $\mathrm{G}_{\mathrm{BD}}$ / RAPl $(653-827)$ is somehow able to circumvent the normal requirement for $S I R 1$.

\section{$G_{B I} /$ rap $1^{s}$ hybrids display no defect in targeted silencing}

Because the silencing-defective rap $1^{\text {s }}$ mutations (Sussel and Shore 1991) fall within the sequences contained in all of the functional $\mathrm{G}_{\mathrm{BD}}$ / RAPl hybrids described above, we decided to introduce the strongest of these mutations (rap1-12, a double mutation at positions 726 and 727) into the $\mathrm{G}_{\mathrm{BD}} / \mathrm{RAP} 1(653-827)$ hybrid and assay its effect on targeted silencing at $H M R$ (see Materials and methods). The construct encoding the mutant hybrid, which we will refer to as $\mathrm{G}_{\mathrm{BD}} / \mathrm{rap} 1-12(653-827)$, was integrated in single copy into the HIS3 locus in a strain containing a $\triangle \mathrm{A} \Delta \mathrm{E}::\left(\mathrm{UAS}_{\mathrm{G}}\right)_{3} h m r:: T R P 1$ reporter gene to give strain YSB 1 10. We chose the $\Delta \mathrm{A} \Delta \mathrm{E}$ silencer because the rap112 mutation displays its phenotype only in the context of an A site mutation (Sussel and Shore 1991). Targeting of the $\mathrm{G}_{\mathrm{BD}} / \mathrm{rap} 1-12(653-827)$ hybrid to a $\Delta \mathrm{A} \Delta \mathrm{E}:\left(\mathrm{UAS}_{\mathrm{G}}\right)$ silencer was expected to mimic the action of full-length rapl-12 at a $\Delta \mathrm{A}$ silencer. Surprisingly, we found that this $\mathrm{G}_{\mathrm{BD}} /$ rap1-12 hybrid displayed no defect in silencing (Fig. $5 \mathrm{~A}$, cf. rows 4 and 6).

We also showed that a set of longer $\mathrm{G}_{\mathrm{BD}} / \mathrm{rap} 1-12$ hybrids (with amino-terminal endpoints at amino acid 562, 588,618 , or 630 ) can establish silencing in both types of double-deletion silencer, hmr::TRP1 strains (YSB2 and YSB35), as judged by at least a 500-fold decrease in the ability to form colonies in the absence of tryptophan (data not shown). Because all of these longer hybrids are transcriptional activators (Hardy et al. 1992a), we conclude that the ability of the $\mathrm{G}_{\mathrm{BD}} / \mathrm{rap} 1-12(653-827)$ hybrid to silence cannot be explained by the absence of a potentially competing activation domain.

Chromosomal rapl-12 mutation abolishes the function of $G_{B D} / R A P 1$ but not $G_{B D} /$ rap $1^{s}$ hybrids

The ability of the $\mathrm{G}_{\mathrm{BD}}$ / rapl-12 hybrids to establish repression when targeted to $H M R$ led us to investigate if the chromosomal rap1-12 mutation could affect $\mathrm{G}_{\mathrm{BD}} /$ RAPl-dependent silencing. To do this, we crossed a strain containing a marked rap1-12 allele (rap112::URA3) to a $\triangle \mathrm{A} \Delta \mathrm{E}::\left(\mathrm{UAS}_{\mathrm{G}}\right)_{3} h m r:: T R P 1$ reporter strain containing the $\mathrm{G}_{\mathrm{BD}} / \mathrm{RAPl}(653-827)$ hybrid gene integrated at HIS3. The resulting diploid was sporulated and dissected to obtain strain YSB74. Strikingly, we found that this strain and several other isogenic segregants containing the rap1-12 allele (Ura ${ }^{+}$) were completely defective in $\mathrm{G}_{\mathrm{BD}}$ /RAPl-mediated silencing, whereas the corresponding RAP1 segregants retained the ability to carry out targeted silencing (Fig. 5A, cf. rows 4 and 51 .

Using the same strategy outline above, we examined the effect of the rap1-12 mutation on silencing established by $\mathrm{G}_{\mathrm{BD}}$ /rapl-12(653-827). Surprisingly, the mutant hybrid protein was unaffected by the rap1-12 mutant background, silencing equally well in both the RAP1 and rap1-12 strains (Fig. 5A, rows 6 and 7). In other words, the rap1-12 mutation in the hybrid protein was able to suppress the targeted silencing defect caused by the very same amino acid substitutions in the chromosomal RAP1 gene (Fig. 5A, cf. rows 5 and 7).

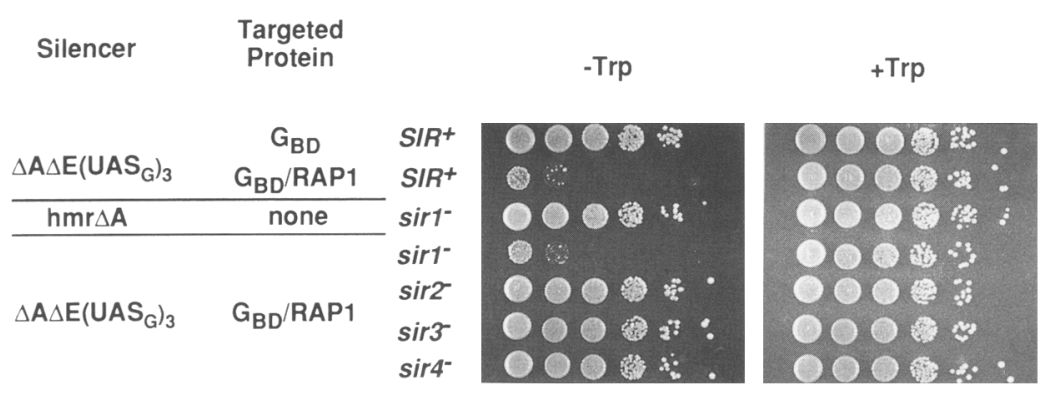

Figure 4. Targeted silencing by $\mathrm{G}_{\mathrm{BD}} / \mathrm{RAPl}$ $(653-827)$ is abolished in sir2, sir3, and sir4 mutants but is unaffected by mutation of SIR 1 . The $S I R^{+}$control strain in the first two rows is YSB2. Mutation of SIR2, SIR3, and SIR4 in this strain background give the same fully derepressed phenotype (data not shown). The sir1, sir2, sir3, sir4 mutant derivatives of YSB2 in rows 4-7 are YSB160, RS1042, RS1061, and RS1067, respectively. Row 3 shows the effect of the $\operatorname{sir} 1$ mutation on native silencing at $h m r \Delta A$ (YDS702) for purposes of comparison. The Trp plating assay was performed as in Fig. 3. 
Figure 5. Effects of the rap1-12 and rif1::URA3 mutations on $\mathrm{G}_{\mathrm{BD}} / \mathrm{RAP} 1(653-827)$ - and $\mathrm{G}_{\mathrm{BD}} /$ rapl12(653-827)-dependent silencing of an hmr::TRP1 reporter. Silencing was assayed as described in Fig. 3 . The strains used in these experiments are described in the text. $(A)$ Targeted silencing by $\mathrm{G}_{\mathrm{BD}} /$ RAP1 $\mid 653-827)$ but not $\mathrm{G}_{\mathrm{BD}} / \mathrm{rapl}-12(653-827)$ is abolished by a chromosomal rap1-12 mutation. Targeted silencing by $\mathrm{G}_{\mathrm{BD}} / \mathrm{RAPl}(653-827)$ (rows 4,5 ) or $\mathrm{G}_{\mathrm{BD}} /$ rapl-12(653-827) (rows 6,7 ) hybrids was examined in strains in which the chromosomal copy of $R A P 1$ was either wild-type (rows 4,6 ) or contained the rap 1-12 allele (rows 5,7). Rows 3 and 8 show that neither the wild-type nor the mutant hybrid can function in the absence of $\mathrm{UAS}_{\mathrm{G}}$ sites at the silencer. Row 1 shows native silencing at an $h m r \Delta A:: T R P 1$ locus, and row 2 shows the effect of the rap1-12 allele on this reporter for purposes of comparison with targeted silencing. $(B)$ A rif1::URA3 gene disruption does not abolish $\mathrm{G}_{\mathrm{BD}} /$ RAP1 (653-827) (rows 4,5) or $\mathrm{G}_{\mathrm{BD}}$ /rap-12(653-827) (rows 6,7 ) targeted silencing. The effect of the rif $1:: U R A 3$ mutation on native silencing at $h m r \Delta A:: T R P 1$ (rows 1,2 ) is shown for comparison.
A

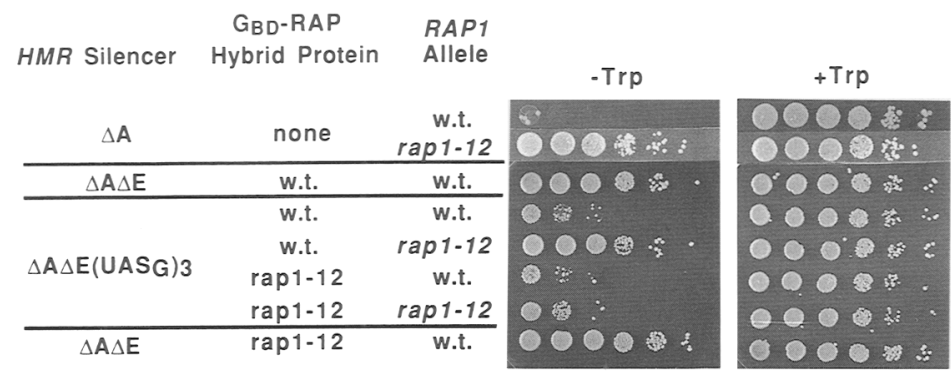

B

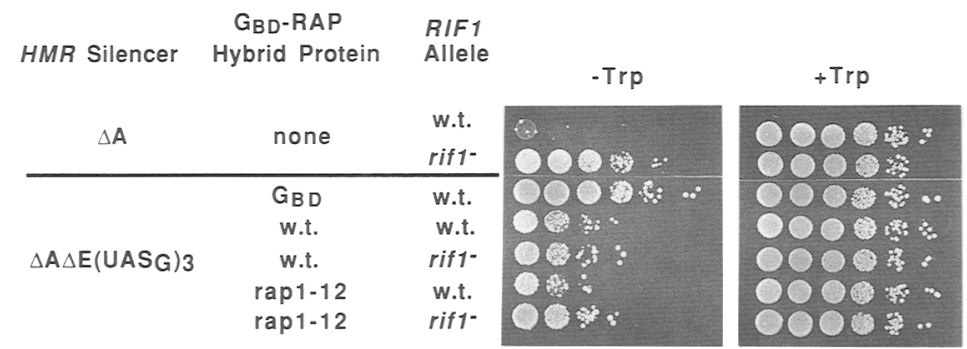

Because rif1 mutants share many of the phenotypes of rap $1^{s}$ mutants and $\mathrm{G}_{\mathrm{BD}} / \mathrm{rap}^{\mathrm{s}}$ hybrid proteins are defective in interacting with RIFl in the two-hybrid system (Hardy et al. 1992b), we also tested the effect of a rif1 mutation on targeted silencing. In a similar set of genetic crosses, targeted silencing strains containing a rif $1:: U R A 3$ mutation were generated. In this case, we found that $\mathrm{G}_{\mathrm{BI}} / \mathrm{RAP} 1(653-827)$-mediated silencing was unaffected by rif1 mutation, because it was indistinguishable from that observed in a RIF1 isolate derived from the same cross (Fig. 5B, cf. rows 4 and 5). The action of the $\mathrm{G}_{\mathrm{BD}} / \mathrm{rap} 1-12(653-827)$ hybrid may have been weakened very slightly by the rif1 mutation (Fig. 5B, cf. rows 6 and 7).

\section{Increasing telomere length diminishes silencing at $\mathrm{HMR}$}

The data described above reveal two puzzling features of the rap1-12 mutation, both of which seem to be inconsistent with the idea that the rap1-12 mutation has a direct effect on $H M R$. First, when targeted to an $H M R-E$ silencer mutated for the A element, $\mathrm{G}_{\mathrm{BD}} /$ rap 1-12 hybrids display no silencing defect (Fig. 5A; data not shown). Second, a chromosomal rap1-12 mutation has a profound effect on targeted silencing [by wild-type $\mathrm{G}_{\mathrm{BD}}$ / RAP1(653-827)] despite the absence of a RAP1 binding site at the $H M R-E$ silencer being tested (Fig. 5A). One explanation for the second observation is that the rap112 protein exerts an indirect effect from some other sites in the chromosome that results in weakened repression at $H M R$. The telomeres are excellent candidates for such sites because it is known that RAPl binds to multiple sites at telomeres (Longtine et al. 1989; Gilson et al. 1993), where it controls both telomere repeat tract length and TPE (Lustig et al. 1990; Sussel and Shore 1991; Kyrion et al. 1992, 1993). Furthermore, rap1" mutations are known to increase telomere length and, presumably, the number of RAP1 molecules bound to these sites (Sussel and Shore 1991). We thus decided to determine whether increased telomere length alone (in RAP1 wild-type cells) is able to diminish targeted silencing at $H M R$.

To produce RAP1 cells containing elongated telomeres, we took advantage of the rap1-17 mutation, a rap $1^{t}$ allele that results in a truncation of the RAPl carboxyl terminus and a pronounced telomere elongation phenotype (Kyrion et al. 1992). When a rap1-17 strain is mated to a $R A P 1$ wild-type strain, the resulting diploid contains elongated telomeres that are inherited by RAP1 haploid cells after sporulation. These elongated telomeres increase TPE in the RAP1 wild-type cells, indicating that telomere length itself influences the strength of TPE (Kyrion et al. 1993). To increase telomere length in strains undergoing targeted silencing at $H M R$, we crossed strain AJL394-2a (rap $\left.1^{t}\right)$ to both YSB80 [expressing $\left.\mathrm{G}_{\mathrm{BD}} / \mathrm{RAP} 1653-827\right)$ and $\mathrm{YSB} 282$ [expressing $\mathrm{G}_{\mathrm{BD}} /$ rapl-12(653-827)]. The resulting diploid strains were sporulated, and haploid segregants were obtained that had a wild-type $R A P 1$ allele and both the cis and trans components of the targeted silencing system. Approximately half of the poly $\left(\mathrm{C}_{1-3} \mathrm{~A}\right)$ telomere tracts is these strains should be extremely elongated, and this was confirmed by Southern blotting (Fig. 6A).

We noticed two different effects on targeted silencing in these strains. First, there was a reproducible 10- to 100-fold decrease in targeted silencing by the $\mathrm{G}_{\mathrm{BD}} /$ RAP1(653-827) hybrid in strains containing elongated telomeres when compared with isogenic strains derived from an identical genetic cross to a RAP1 control strain 
A
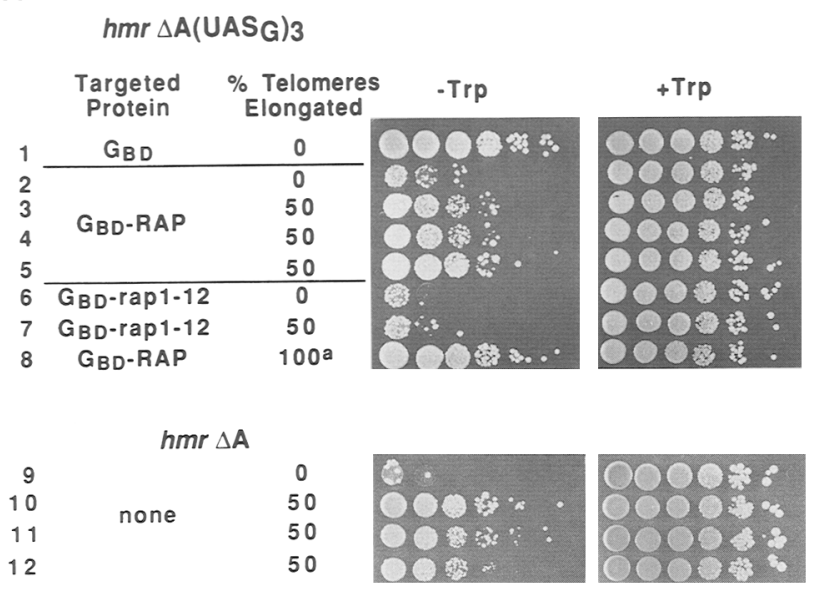

B

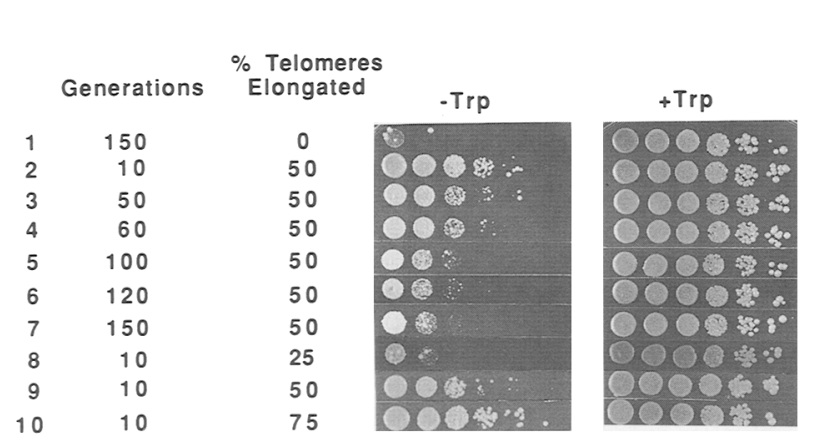

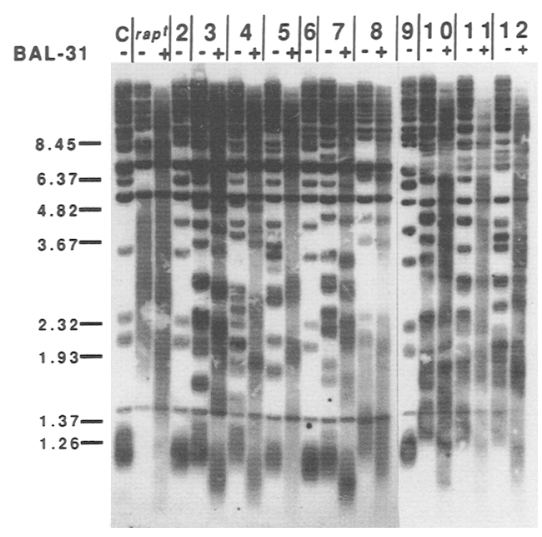

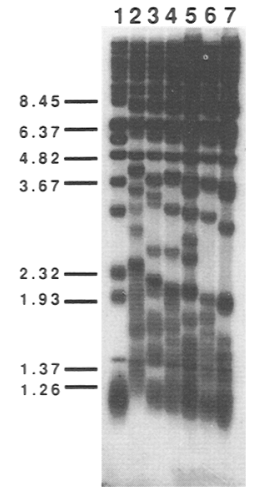

Figure 6. Elongated telomeres antagonize $h m r:: T R P 1$ silencing in a reversible and dosage-dependent manner. Silencing was assayed as described in Fig. 3. Elongated telomeres are inherited from a rap $1^{t}$ parent strain in a genetic cross, and the dosage of elongated telomeres is predicted from the genotype of the parent strains (see text). Telomeres of relevant strains were analyzed by Southern blotting (shown at right of the silencing assays), and in many cases genomic DNA was treated with the exonuclease BAL31 before restriction digestion to demonstrate that bands with altered mobilities actually represent telomeric sequences. Numbers above the lanes correspond to the numbered rows in the silencing assay. Size markers are shown at left of the Southern blot (in kilobase pairs). (A) Elongated telomeres antagonize both $\mathrm{G}_{\mathrm{BD}}$ / RAP 1(653-827) targeted silencing (rows 3-5) and hmr $\Delta A$ silencing (rows 10-12) but have little effect on $\mathrm{G}_{\mathrm{BD}} /$ rapl-12(653-827) targeted silencing (row 7). ( ${ }^{\text {a) }}$ Targeted silencing by $\mathrm{G}_{\mathrm{BD}} / \mathrm{RAPl}(653-827)$ in a rap1-12 strain is shown (row 8 ) for purposes of comparison (see also Fig. 5A, row 5). In this strain all of the telomeres are elongated because of the rap1-12 mutation. The new strains used in this figure are as follows: Rows 2-7 are YSB284, YSB285, YSB286, YSB287, YSB288, and YSB289, respectively; rows 9-12 are YSB290, YSB291, YSB292, and YSB293, respectively; lane C is AJL275-2a (a RAP1 control), and the rap $1^{t}$ lanes are AJL394-2a. (B) Derepression of $h m r \Delta A$ by elongated telomeres is reversed by continuous subculturing and is sensitive to the dosage of elongated telomeres. YSB291 was grown in liquid YEPD medium at $30^{\circ} \mathrm{C}$ and at various time points assayed for silencing and telomere length (rows 2-7). Elongated telomere dosage of YSB293 was altered by genetic crosses (see text) to create strains YSB296, YSB297, and YSB298 (rows 8-10, respectively).

(Fig. 6A, cf. rows 3-5 with row 2). This result suggests that an increase in the length of telomeric poly $\left(\mathrm{C}_{1-3} \mathrm{~A}\right)$ tracts is by itself sufficient to decrease the efficiency of targeted silencing. However, we found that targeted silencing by the $\mathrm{G}_{\mathrm{BD}} / \mathrm{rap1-12(653-827)}$ hybrid is only weakly affected by telomere elongation (Fig. 6A, cf. rows 6 and 7) and is considerably stronger than that of the wild-type hybrid in the presence of elongated telomeres (Fig. 6A, cf. row 7 with rows 3-5). This observation indicates that the mutant hybrid is more resistant to the effect of telomere elongation than the wild-type hybrid and is consistent with the previous observation (Fig. 5A) that the rap1-12 mutant hybrid suppresses the defect caused by the chromosomal rap1-12 allele.

We also examined the effect of elongated telomeres on normal silencing at $H M R$. The rap1-17 strain was crossed to strains containing a $h m r:: T R P 1$ reporter with either a wild-type, $h m r \Delta A$, or $h m r \Delta B$ silencer. All $R A P 1$ $h m r \Delta A$ haploid segregants from these crosses displayed a defect in silencing (Fig. 6A, rows 10-12; data not shown). 
Consistent with the characterization of the rap1-12 mutation, elongated telomeres do not affect either the wildtype or the $\triangle \mathrm{B} H M R-E$ silencer (data not shown).

We performed two additional experiments to test the idea that telomere elongation, and, hence, increased amounts of RAPl-binding poly $\left(\mathrm{C}_{1-3} \mathrm{~A}\right)$ sequence, is responsible for diminished silencing at $H M R$. First, we continuously subcultured strain YSB291, shown in Figure $6 \mathrm{~A}$, which results in a gradual ( $\sim 2$ bp per generation) shortening of the elongated telomeres derived from the rap $1^{t}$ parent (Kyrion et al. 1992). During the course of this subculturing, we observed a continuous improvement in targeted silencing at $H M R$ that correlated with the progressive loss of telomeric poly $\left(\mathrm{C}_{1-3} \mathrm{~A}\right)$ sequences (Fig. 6B, rows $2-7$ ). In a separate experiment, we performed genetic crosses to generate strains containing different numbers, on average, of elongated telomeres. If telomeric $\mathrm{C}_{1-3} \mathrm{~A}$ repeats act in trans to derepress $H M R$, then increasing the dosage of elongated telomeres would be expected to create a more severe phenotype, whereas a reduction of elongated telomeres should have the opposite effect. To increase the dosage of elongated telomeres, strain YSB293 (in which approximately one half of the telomeres should be elongated) was crossed to AJL440-1c (rap 1 $\left.{ }^{t}\right)$ and sporulated to generate haploid segregants containing, on average, a 0.75 dosage of elongated telomeres. All nine such segregants examined displayed a more severe silencing defect than the parent strain (YSB293) or a strain derived from a control cross (YSB297) (Fig. 6B, row 10; data not shown). Similarly, YSB293 was crossed to a RAP1 strain, and haploid segregants were obtained tht should have an average 0.25 contribution of elongated telomeres. All 11 such segregants examined displayed clearly stronger repression than the YSB293 parent (Fig. 6B, row 8; data not shown). These data further support the idea that the overall amount of telomeric poly $\left(\mathrm{C}_{1-3} \mathrm{~A}\right)$ sequence determines the extent of derepression at $H M R$ and argues against the possibility that the effect may be the result of some specific change at the right arm of chromosome III, where the HMR locus is $\sim 25 \mathrm{~kb}$ from the telomere (Oliver et al. 1992).

\section{SIR4 protein is limiting in targeted silencing} by $G_{B D} / R A P 1$ hybrids

Initial characterization of the rap1-12 mutation showed that it can be suppressed by elevated gene dosage of either SIR1 or SIR4 (Sussel and Shore 1991). This result is striking in the case of SIR 4 because the effect of extra copies of this gene in a RAP1 wild-type strain is actually derepressing. To examine the effect of increased SIR1 and SIR4 gene dosage on targeted silencing in rap1-12 strains, we initially introduced the $S I R 1$ or $S I R 4$ genes on multicopy (2- $\mu \mathrm{m}$ origin) plasmids. No improvement in the ability of the $\mathrm{G}_{\mathrm{BD}} / \mathrm{RAPl}(653-827)$ hybrid to silence in a rap1-12 strain was observed (data not shown). Furthermore, elevated SIR4 dosage abolished targeted silencing by $\mathrm{G}_{\mathrm{BD}} / \mathrm{RAP1}(653-827)$ and $\mathrm{G}_{\mathrm{BD}} / \mathrm{rap} 1-12(653-$ $827)$ hybrids in a RAP1 background and by the $\mathrm{G}_{\mathrm{BD}} / \mathrm{rapl}$ -
12(653-827) hybrid in a rap1-12 background. The SIR1 plasmid had no effect in any of these conditions. We then examined the effect of adding the SIR4 and SIR1 genes on a low-copy (CEN) plasmid, because it had been shown previously that a single extra copy of SIR4 is sufficient to suppress the rap1-12 mutation (Sussel et al. 1993). This modest increase in $S I R 4$ gene dosage improved $\mathrm{G}_{\mathrm{BD}} /$ RAP1 (653-827) silencing (in a RAP1 background) to the level produced by native RAPl at a $h m r \Delta A$ silencer (Fig. 7, row 2; cf. with 5A, row 1). Furthermore, the SIR4 CEN plasmid partially suppressed the defect caused by the chromosomal rap1-12 mutation, enabling $\mathrm{G}_{\mathrm{BD}} /$ RAP1 $(653-827)$ to give -50 - to 100 -fold repression in the TRP1 reporter assay (Fig. 7, row 4). The CEN-SIR1 plasmid had no effect in either of these strains (Fig. 7, row 3; data not shown).

\section{The rap1-12 mutation improves telomeric silencing} and has a strengthened interaction with SIR4

The experiments described above suggest that diminished targeted silencing in rap1s strains may be attributed at least in part to telomere elongation. If telomere elongation in rap1-12 strains results in a competition for limiting silencing factors with $H M R$, one might expect to observe improved telomeric silencing in these strains. To test this idea, we constructed $\triangle \mathrm{A} h m r$ TRP1 strains in which the telomere on the left arm of chromosome VII is altered to contain a URA3 gene followed by terminal $\left(\mathrm{C}_{1-3} \mathrm{~A}\right)$ repeat sequences at the $A D H 4$ locus (Gottschling et al. 1990). The telomeric URA3 reporter gene is subject to silencing (TPE) that results in repression of the gene in $\sim 50 \%$ of the cells in a culture. This variegated repression can be best quantified by measuring the ability of these cells to grow in the presence of 5-fluoro-orotic acid (5-FOA), which kills cells expressing the URA3 gene $\left(\mathrm{FOA}^{\mathrm{R}}\right.$, or repressed phenotype). As shown in Table 2, telomeric repression of URA3 is significantly improved in rap1-12 strains compared with isogenic $R A P 1^{+}$strains, as indicated by both an increased ability to grow in the presence of FOA and re-

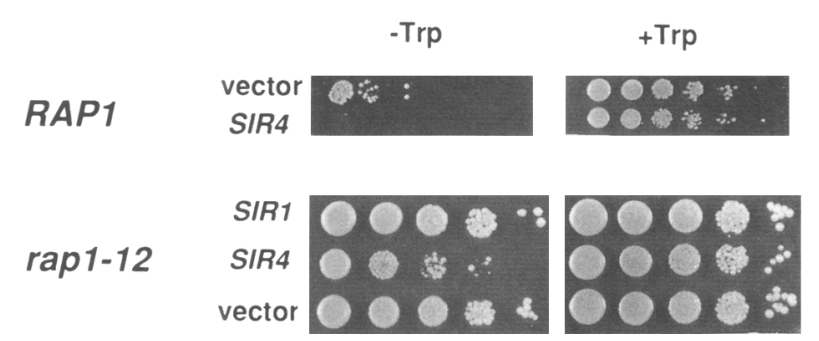

Figure 7. The SIR4 gene on a CEN plasmid improves $\mathrm{G}_{\mathrm{BD}}$ / RAP1(653-827)-mediated silencing in a RAP1 strain (YSB107). SIR4-CEN, but not SIR1-CEN, partially suppresses the targeted-silencing defect of $\mathrm{G}_{\mathrm{BD}} / \mathrm{RAPl}(653-827)$ in a rap1-12 strain (YSB143). Rows labeled vector represent strains transformed with the CEN vector alone, whereas those marked SIR1 or SIR4 are strains containing the CEN vector with the indicated $S I R$ gene. 
Table 2. Effect of the rap1-12 mutation on telomere position effect

\begin{tabular}{lccc}
\hline Strain & RAP1 allele & $\begin{array}{c}\text { Growth on } \\
- \text { Ura }^{\mathrm{a}}(\%)\end{array}$ & $\begin{array}{l}\text { Growth on } \\
\text { FOA }^{\mathrm{a}}(\%)\end{array}$ \\
\hline YSB215 & RAP1 $^{+}$ & $37.6(7.2)$ & $56.4(13.2)$ \\
YSB216 & rap1-12 & $9.8(2.7)$ & $95.4(6.3)$ \\
\hline
\end{tabular}

${ }^{a}$ Compared to an equal aliquot of cells plated on YEPD (rich) medium. The values in parentheses are standard deviations. The values are averages from measurements of six independent colonies from each strain.

duced growth in the absence of uracil. This improvement of telomeric silencing is accompanied by a complete loss of $\triangle \mathrm{A} h m r$ TRP1 repression, as evidenced by the full growth of this strain in the absence of tryptophan (data not shown).

Two observations suggest that the effect of the rap1-12 mutation at $H M R$ is the result of more than telomere elongation alone. First, the defect caused by the inheritance of elongated telomeres from a rap $1^{t}$ strain appears less severe than that caused by rap1-12, although the extent of $\mathrm{C}_{1-3} \mathrm{~A}$ expansion appears to be greater in the former case (Fig. 6). Second, the $\mathrm{G}_{\mathrm{BI}}$ / $/$ rapl-12/653-827) hybrid can act directly at a $H M R-E$ silencer to suppress the defect caused by the rap1-12 allele (Fig. 5A). One possible explanation of these results, based on the sensitivity to SIR4 gene dosage described above, is that the rap1-12 mutation leads to an altered interaction with the SIR4 protein that can by itself contribute to a shift in the balance between $H M R$ and telomeric silencing. To test this idea, we took advantage of the recent observation that the RAPl carboxyl terminus can interact with the carboxyl terminus of SIR4 in the two-hybrid system (Moretti et al. 1994). We therefore determined whether the RAP1-SIR4 interaction is affected by the rap1-12 mutation. To do this, we constructed a LexA/rap112(635-827) hybrid and compared it with the corresponding LexA/RAP1(635-827) hybrid in a two-hybrid assay with a GAL4 activation domain $\left(G_{A I}\right) /$ SIR4 hybrid. As shown in Table 3, the mutant rapl-12 hybrid interacts much more strongly with SIR4 than does the wild-type LexA/RAPl hybrid, as indicated by an $\sim 20$ - fold increase in $\beta$-galactosidase activity. This experiment was repeated in a rif $1:: U R A 3$ reporter strain to test the idea that the increase in the interaction with SIR 4 is the result of a decreased interaction between rap1-12 protein and RIF1 (Hardy et al. 1992b). The rif1::URA3 disruption increases the ability of LexA/RAP1(635-827) to activate by itself (Moretti et al. 1994), but the SIR4/ $\mathrm{G}_{\mathrm{AD}}$ hybrid gene increases the $\beta$-galactosidase signal above this background level. Strikingly, the rap1-12 mutation still resulted in a large (approximately fivefold) increase in the interaction with $\operatorname{SIR} 4 / \mathrm{G}_{\mathrm{AD}}$ compared with the wild-type hybrid (Table 3). This increase represents a 47 -fold increase above the $\left(G_{A D}\right.$ only) control, whereas the wild-type hybrid displayed a 3 -fold increase above the $\left(\mathrm{G}_{\mathrm{AD}}\right.$ only) control. Therefore, the increase in the interaction of SIR4/G $\mathrm{G}_{\mathrm{AD}}$ with LexA/rap1-12/635827) cannot be explained by the failure of the mutant hybrid to interact with RIF1, a potential competitor for SIR4 binding. We also noticed that the rif1 mutation created a much smaller increase in the activation potential of the LexA/rap1-12(635-827) hybrid compared with the corresponding wild-type hybrid. Taken together, these results are consistent with the idea that the rap112 mutation strengthens the interaction between RAPl and SIR4 and suggest that the phenotypes of rap1-12 strains described above result at least in part from an improved ability of telomeric rapl-12 protein to bind a limiting amount of SIR4 protein. It is important to point out, however, that these two-hybrid experiments measure a RAP1-SIR4 interaction in a different context than that of $H M R$ or telomeres, as reflected by the fact, for example, that we do not detect an interaction between the $\mathrm{G}_{\mathrm{B1}}$ /RAP1(653-827) hybrid and the small carboxyterminal fragment of SIR4 used in the two-hybrid assays (data not shown). We cannot be certain, therefore, that the two-hybrid results precisely reflect the interactions that occur at silencers and telomeres.

\section{Discussion}

\section{A minimal RAP1 silencing domain}

The use of $\mathrm{G}_{\mathrm{BD}}$ /RAPI hybrids has allowed us to define a minimal domain of RAP1 (amino acids 667-827) that is

Table 3. Interaction of $G_{A D} / \operatorname{SIR} 4$ with $G_{B D} / R A P 1$ and $G_{B D} /$ rap $1^{\text {s }}$ hybrids

\begin{tabular}{|c|c|c|c|}
\hline \multirow{2}{*}{$\begin{array}{l}\text { DNA-binding domain } \\
\text { hybrid }\end{array}$} & \multirow{2}{*}{$\begin{array}{l}\text { Activation domain } \\
\text { hybrid }^{\mathrm{a}}\end{array}$} & \multicolumn{2}{|c|}{$\beta-$ Gal units $^{\mathrm{b}}$} \\
\hline & & $R I F 1$ & rif1::URA3 \\
\hline LexA/RAP1(635-827) & $\mathrm{G}_{\mathrm{AD}}$ alone & $7(2)$ & $94 \quad(5)$ \\
\hline LexA/RAPl(635-827) & $\mathrm{G}_{\mathrm{AD}} / \mathrm{SIR} 4$ & $89 \quad(6)$ & $270(11)$ \\
\hline LexA/rap 1-12(635-827) & $\mathrm{G}_{\mathrm{AD}}$ alone & $15 \quad(2)$ & $29 \quad(2)$ \\
\hline LexA/rap 1-12(635-827) & $\mathrm{G}_{\mathrm{AD}} / \mathrm{SIR} 4$ & $1913(28)$ & $1360(123)$ \\
\hline
\end{tabular}

${ }^{\mathrm{a}} \mathrm{G}_{\mathrm{AD}}$ /SIR4 was isolated from a library of yeast genomic partial Sau3A fragments cloned into the pGAD3 vector (Chien et al. 1991). (The library was a generous gift of P. Bartel and S. Fields.) The $G_{A D} / S I R 4$ hybrid consists of amino acids $1204-1358$ of SIR4 fused in-frame to the GAL4 activation domain (Moretti et al. 1994).

bThe numbers are an average of the values obtained for three independent transformants. The values in parentheses are the standard deviations. 
sufficient to establish transcriptional silencing, in the absence of any other RAP1 sequences, when targeted to the HMR locus. This conclusion is consistent with previous results showing that point mutations in this region $\left(\right.$ rap $\left.^{s}\right)$ and overexpression of the wild-type domain cause derepression of $H M R$ (Sussel and Shore 1991; Hardy et al. 1992a) and that truncations of this domain abolish silencing at $H M L$ and telomeres (Kyrion et al. 1993). The dependence on SIR2, SIR3, and SIR4 function indicates that the effect of $\mathrm{G}_{\mathrm{BD}} / \mathrm{RAP1}$ hybrids is bona fide silencing rather than a nonspecific effect on the $H M R$ locus. It is worth pointing out that the $\mathrm{G}_{\mathrm{BD}} / \mathrm{RAP} 1(653-827)$ hybrid is incapable of acting as a transcriptional activator when targeted to the promoter of a reporter gene (Hardy et al. 1992a). The fact that this hybrid still requires SIR2, $S I R 3$, and SIR4 in silencing rules out a model in which the only role for one (or all) of these silencing factors is to block the activation function of RAP1 at $H M R$.

Several of the $\mathrm{G}_{\mathrm{BD}}$ /RAPI hybrids described here contain a RAP1 transcriptional activation domain (Hardy et al. 1992a) yet still function as repressors when targeted to $H M R$. This result reinforces the conclusion from previous studies that the activity of RAP1 is context dependent (Buchman et al. 1988b; Shore and Nasmyth 1987) and shows for the first time that a small carboxy-terminal part of the protein (exclusive of its DNA-binding domain) is sufficient to carry out the correct context-dependent function (activation or silencing) when fused to a heterologous DNA-binding domain. Exactly how the $H M R$ context influences the action of $\mathrm{G}_{\mathrm{BI}} / \mathrm{RAPl}$ hybrids is unknown. It seems unlikely that the $A$ or $B$ sites at $H M R-E$ are strictly required to promote RAP1's silencing function nor are they necessary to antagonize the activation function of RAPl, as $G_{B 1}$ / RAPl hybrids are able to establish repression in their absence. However, both the A and B sites contribute to targeted silencing when GAL4-binding sites are limiting, suggesting that they either cooperate with $G_{\mathrm{BD}} / \mathrm{RAPl}$ or act independently to establish silencing.

\section{SIR1-dependent and SIR1-independent silencing}

SIR1 is required for stable repression at $H M$ loci (Rine and Herskowitz 1987; Pillus and Rine 1989) yet has no apparent role in TPE (Aparicio et al. 1991). It is thus somewhat surprising that targeted silencing by $\mathrm{G}_{\mathrm{BD}} /$ RAP1 hybrids at HMR is completely independent of SIR1 function. Using the same targeting strategy described here, it was shown previously that a $\mathrm{G}_{\mathrm{BD}}-\mathrm{SIR} 1$ hybrid can function at the HMR-E silencer to establish repression, leading to the suggestion that $H M$ silencers have a special mechanism to recruit SIRl that is missing from telomeres (Chien et al. 1993). Considered in this light, the SIR1 independence of targeted silencing by $\mathrm{G}_{\mathrm{BD}} / \mathrm{RAPl}$ hybrids at $H M R-E$ may be the result of a failure to recruit SIR1 protein to the mutated silencer. This notion is supported by the additional observations that elevated SIR1 gene dosage neither improves silencing by $\mathrm{G}_{\mathrm{BD}} / \mathrm{RAPl}$ hybrids nor does it suppress the defect in targeted silencing in a rap1-12 strain. In contrast, extra copies of SIR1 can suppress the silencing defect of a rap1$12 \mathrm{hmr} \Delta A$ strain (Sussel and Shore 1991) and several other cis- and trans-acting mutations affecting $H M R$ (Stone et al. 1991). Although the precise reason for this is unclear, it seems that some feature of $\mathrm{G}_{\mathrm{BD}} / \mathrm{RAP1}$ hybrids that differs from native RAPl must explain this observation. Several possibilities can be considered. The $\mathrm{G}_{\mathrm{BD}}$ /RAP1 hybrids studied here may display the RAP1 carboxyl terminus in a way that is unfavorable for SIR 1 binding to HMR.E. Alternatively, these RAPl hybrids may be lacking sequences required to localize SIR 1 to the HMR-E silencer. For example, SIRl may make contacts with the RAP1 DNA-binding domain, which is not present on our $\mathrm{G}_{\mathrm{BD}} / \mathrm{RAP} 1$ hybrids. Another possibility is that DNA bending induced by the RAP1 DNA-binding domain (Vignais and Sentenac 1989; Gilson et al. 1993) is important for SIR1 recruitment at HMR-E and is not provided by the GAL4 DNA-binding domain in the $\mathrm{G}_{\mathrm{BD}} /$ RAPl hybrids.

Whatever the explanation for the SIR1 independence of $\mathrm{G}_{\mathrm{BD}} / \mathrm{RAPl}$ silencing, it is clear that the role of $\mathrm{G}_{\mathrm{BD}} /$ RAPl hybrids is not to recruit SIR 1 to the silencer. In fact, $\mathrm{G}_{\mathrm{BD}} / \mathrm{RAPl}$ and $\mathrm{G}_{\mathrm{BD}}-\mathrm{SIR} 1$ hybrids seem to be functionally redundant. We consider two general models to explain these observations. The first model proposes that the two hybrids carry out the same function, that is, to recruit silencing factors (e.g., SIR3 and SIR4) to $H M R$ (Moretti et al. 1994). An opposing view is that $\mathrm{G}_{\mathrm{BD}^{-}}-\mathrm{SIR} 1$ possesses an establishment mechanism distinct from the function of the carboxyl terminus of RAPl. Several properties of the two silencing systems are consistent with the latter model. Overexpression of $\mathrm{G}_{\mathrm{BD}} / \mathrm{RAPl}$ hybrids has a dominant-negative effect on silencing at $H M R$, probably by titration of SIR3 and SIR4, whereas $\mathrm{G}_{\mathrm{BD}}$ SIR1 has no such effect. In addition, although the rap112 mutation is antagonistic to $\mathrm{G}_{\mathrm{BD}} / \mathrm{RAPl}$ silencing, it has no effect on silencing by $\mathrm{G}_{\mathrm{BD}}-\mathrm{SIR} 1$ (data not shown). Taken together, the data in this report indicate that a special feature of the $H M R-E$ silencer is required for SIR 1 function and provide further support for the idea that a normal site of action of SIR 1 is the HMR-E silencer. The targeted silencing system described here clearly lacks the ability to utilize SIR1 and therefore shares several properties in common with telomeric silencing.

\section{rap $1^{\mathrm{s}}$ mutations reveal an underlying competition between HMR and telomeric silencing}

The rap1-12 mutation is one of four rap $1^{s}$ alleles identified originally in a screen for RAP1 mutations that result in derepression of the $H M R$ silent locus. It only displays this phenotype when the redundancy of the HMR-E silencer is eliminated by mutation of the ACS (A element) at $H M R-E$ (Sussel and Shore 1991). The observation that mutation of the RAP1-interacting factor RIF1 also creates an $h m r \Delta A$-specific silencing defect led to the proposal that rap $1^{s}$ mutations (of which rap1-12 is the most severe) create a defect in the ability of RAP1 to recruit RIF1 to silencers, which results in a loss of repression when the silencer is weakened by the $\Delta \mathrm{A}$ mutation 
(Hardy et al. 1992b). Consistent with this idea, the $\mathrm{G}_{\mathrm{BD}}$ / rap $1^{\text {s }}$ hybrids display a decrease in RIF1 binding in the two-hybrid system that is proportional to the severity of the corresponding rap $1^{s}$ defect in silencing.

Characterization of the rap1-12 mutation reported here resulted in several unexpected findings that challenge this interpretation of the rap $1^{s}$ and rif1 mutations. First, we showed that targeting of the $\mathrm{G}_{\mathrm{BD}} / \operatorname{rap} 1-12 / 653-$ $827)$ hybrid to $H M R-E$ does not result in a loss of silencing as predicted by the model. In fact, targeting the rapl12 mutant often improves the efficiency of repression relative to the wild-type $\mathrm{G}_{\mathrm{BD}} / \mathrm{RAPl}$ hybrid /Figs. 5 and 6 . Second, the presence of the rap1-12 mutation in the chromosome prevents silencing by $\mathrm{G}_{\mathrm{BD}} / \mathrm{RAP1}(653-827)$, even though the silencers tested lack a binding site for native rap 1-12 protein. Finally, we showed that the rap112 mutation, which abolishes repression by an $h m r \Delta A$ silencer, actually improves telomeric silencing.

On the basis of these new results, we propose that effects of the rap1-12 mutation at telomeres lead to a loss of repression at the $h m r \Delta A$ silencer. Several additional observations suggest that a simple competition model may account for this shift in the balance between $H M R$ and telomeric silencing. In rap1-12 strains, the telomeric $\mathrm{C}_{1-3} \mathrm{~A}$ repeats, which contain a high density of RAPlbinding sites (Gilson et al. 1993), increase in length by $\sim 50 \%$ (Sussel and Shore 1991). Previous studies (Kyrion et al. 1993) showed that telomere elongation in wild-type cells can result in improved TPE, similar to that which we have observed in rap1-12 strains. In addition, we showed that an increase in telomere length in RAP1 cells impairs both targeted and native silencing at $H M R$ when the ACS at the HMR-E silencer is mutated. Therefore, the telomere elongation phenotype of the rap 1-12 mutation might, in principal, be sufficient to explain the effect of this mutation at $H M R$. Taken together, these data suggest that in rap1-12 strains telomeres may compete more effectively for silencing factors present in limiting amounts and thereby diminish repression at $H M R$. It is worth noting at this point that the effect of the rap1-12 mutation may result from more than just telomere elongation (see below). One indication of this is that RAP1 wild-type cells containing elongated telomeres appear to have greater amounts of poly $\left(\mathrm{C}_{1-3} \mathrm{~A}\right)$ sequence than rap112 strains yet display a weaker $H M R$ derepression phenotype (Fig. 6).

One apparent paradox of our results is the ability of targeted $\mathrm{G}_{\mathrm{BD}} / \mathrm{rapl}-12(653-827)$ to silence at $H M R$ in rap1-12 strains, a condition analogous in many respects to a normal rap1-12 strain where the mutant rapl-12 protein fails to establish repression at an $h m r \Delta A$ silencer. We believe that a likely explanation for this result is that the targeting system provides multiple copies of the RAPl carboxyl terminus in tandem at $H M R-E$, where the $\mathrm{G}_{\mathrm{BD}} /$ rap1-12(653-827) hybrid can successfully compete for a limiting silencing factor, most likely SIR4 protein (see below). Even silencers containing only a single $\mathrm{UAS}_{\mathrm{G}}$ probably allow for the binding of a $\mathrm{G}_{\mathrm{BD}} / \mathrm{RAP1}$ dimer, whereas a native silencer contains only one binding site for RAP1. In support of this argument, we have shown clearly that the targeting system establishes silencing more efficiently when there are multiple $\mathrm{UAS}_{\mathrm{G}}$ sites at $H M R-E$. A testable prediction of this model is that multiple RAP1 binding sites would improve silencing at $H M R$ in rap $^{s}$ strains.

\section{The role of SIR4 and RIF1 in the regulation of silencing at HMR and telomeres}

Several lines of evidence suggest that derepression at HMR in rap1-12 strains results from an inability of the $h m r \Delta A$ silencer to recruit a limiting amount of SIR 4 protein, which becomes sequestered at telomeres. To begin with, silencing at $H M R$ is extremely sensitive to the gene dosage of SIR4: Diploid strains containing only one copy of the gene display unstable repression, whereas extra copies of $S I R 4$ (on a $2-\mu \mathrm{m}$ plasmid) are sufficient to suppress the silencing defect of rap $1^{\text {s }}$ mutants (Sussel and Shore 1991; Sussel et al. 1993). As shown here, the defect in $\mathrm{G}_{\mathrm{BD}} / \mathrm{RAP} 1(653-827)$ targeted silencing in a rap1-12 strain is also relieved by increasing SIR4 dosage. Furthermore, RAP1 interacts with SIR4 in the two-hybrid system (Moretti et al. 1994), and this interaction is significantly strengthened when the RAPl hybrid contains the rap1-12 missense mutation (Table 3). All of these data, together with the effect of telomere elongation (Sussel and Shore 1991), support the idea that SIR4 is concentrated at telomeres in rap1-12 strains, reducing by mass action the amount available for binding to $H M R$.

This new interpretation of the rap $1^{s}$ mutants suggests, in turn, a different view of the role of RIFl in silencing (Hardy et al. 1992b). We propose, as suggested previously (Kyrion et al. 1993), that RIFl acts as a negative regulator of RAP1's silencing function at telomeres by binding to the RAPl carboxyl terminus and interfering with RAP1SIR interactions. Consistent with this notion, rif1 mutants display improved telomeric silencing reminiscent of that seen in rap1 ${ }^{\text {s }}$ strains (Kyrion et al. 1993). The idea that RIFl interferes with RAP1-SIR interactions is supported by two-hybrid results reported here and elsewhere (Moretti et al. 1994). We imagine that the effect of rif1 mutations on $h m r \Delta A$ silencing is therefore the result of telomere competition for a limiting amount of SIR4, as outlined above. The SIRl-dependent form of silencing that normally operates at $H M$ loci is apparently resistant to any negative effect of RIF1, perhaps by preventing access of RIFl to the silencer. Alternatively, it is conceivable that RIF1 has an opposite effect at $H M R$, that is, to promote silencing. At present, we cannot distinguish between these two possibilities.

It is important to emphasize that although the loss of RIF1 binding and telomere elongation might in principle be sufficient to explain the rap1-12 phenotype, several observations suggest that the effect of this mutation is more complex. For example, in the two-hybrid assay for the RAP1-SIR4 interaction, a large difference is still observed between $\mathrm{G}_{\mathrm{BD}} / \mathrm{RAP1}(653-827)$ and $\mathrm{G}_{\mathrm{BD}} / \mathrm{rap} 1$ 12(653-827) hybrids in cells lacking RIF1. In addition, a rif1 mutation has a significantly weaker effect on tar- 
geted silencing than does the rap1-12 mutation, indicating again that the rap1-12 defect is not a result simply of the loss of the RIF1 interaction. Both of these results suggest that the rap1-12 protein has an intrinsically higher affinity for SIR4 or that this interaction is affected in vivo by other RAP1-interacting proteins, such as SIR3 (Moretti et al. 1994). Furthermore, because rif1 and rap112 mutants have nearly identical telomere lengths (Hardy et al. 1992b), the different effect of these mutations on targeted silencing provides additional support for the claim that the effect of the rap1-12 mutation on $H M R$ cannot be completely accounted for by telomere elongation.

Previous work indicated that SIR1 acts at HM loci to raise repression above a basal level seen at telomeres (Pillus and Rine 1989; Aparicio et al. 1991; Chien et al. 1993), creating a hierarchy of silencing in which $H M$ loci are more efficiently repressed than telomeres. Our characterization of the rap1-12 mutation suggests that this hierarchy may also result from two other effects: negative regulation of RAP1 at telomeres by RIFl and a limiting amount of SIR proteins available to establish repressed chromatin. At telomeres, repression is limited by the availability of SIR3 (Renauld et al. 1993), whereas a weakened $H M R$ locus readily becomes limited for SIR4 protein. We suggest that yeast are restricted in the total amount of SIR-repressed chromatin that they can form. This limitation could have significance for the proper regulation of silencing, perhaps controlling the distance that a particular silenced domain spreads and preventing genes from becoming inappropriately repressed. Our results also suggest that the redundancy of the $H M R-E$ silencer, specifically the presence of the ACS, may play an important role in preventing the normal fluctuations in telomere repeat length from causing derepression of the $H M R$ mating-type locus.

\section{Materials and methods}

Yeast strains and methods

Standard methods of yeast genetics and molecular biology were used throughout (Rose et al. 1990). The yeast strains used in this study are listed in Table 1 . The same $\mathrm{UAS}_{\mathrm{G}}$ oligonucleotide (TCGACGGAGGACAGTCCTCCG and its complement TCGACGGAGGACTGTCCTCCG) was used in the construction of all $\mathrm{UAS}_{\mathrm{G}}$-containing mutated silencers. Details of the silencer deletions (all of which are marked by a XhoI linker) can be found in Brand et al. (1987). UAS $\mathrm{G}_{\mathrm{G}}$ insertions were confirmed by DNA sequencing before transplacement into the HMR locus (Brand et al. 1985). All transplacements were confirmed by Southern blotting. Assays for silencing using the hmr::TRP1 reporter were performed by spotting 10 -fold serial dilutions of cultures grown in liquid YEPD medium or appropriate synthetic (SC) selective medium as described (Sussel and Shore 1991).

\section{Plasmid DNA}

All $\mathrm{G}_{\mathrm{BD}} / \mathrm{RAP1}$ constructs contained the native RAP1 promoter upstream of $G A L 4$ coding sequences. $\mathrm{G}_{\mathrm{BD}} / \mathrm{RAPl}$ fusions in the HIS3 integrating vector pRS303 (Sikorski and Hieter 1989) were described previously (Hardy et al. 1992a). The same $\mathrm{G}_{\mathrm{BD}} / \mathrm{RAP1}$ constructs were transferred to the HIS3/CEN plasmid pRS313 (Sikorski and Hieter 1989) as EcoRI-XbaI fragments. LexA/ RAPl and LexA/rapl-12 hybrid proteins were expressed from plasmid pBTM116 (2- $\mu \mathrm{m}$ origin, TRP1, pADH1-LexA; a gift of P. Bartel and S. Fields, State University of New York, Stony Brook). The SIR4 2- $\mu \mathrm{m}$ plasmid (LSD357) consists of an EcoRISall fragment of SIR4 cloned into pRS426 (Sikorski and Hieter 1989). SIR4/CEN and SIR1/CEN plasmids consist of EcoRI-SalI and KpnI-HindIII fragments, respectively, cloned into pRS316 (Sikorski and Hieter 1989).

\section{RNA analysis}

Total yeast RNA was prepared and analyzed by Northern blotting using standard procedures (Ausubel et al. 1987). hmr al mRNA was detected by probing with a random-primed 650-bp XhoI-BglII DNA fragment from D401 (Xhol linker mutant number 238; Abraham et al. 1984). The blot was reprobed with a 500-bp EcoRI-HindIII fragment from the actin gene.

\section{Detection of poly $\left(C_{1-3} A\right)$ telomeric repeats}

Telomeric poly $\left(\mathrm{C}_{1_{-3}} \mathrm{~A}\right)$ repeats were detected by Southern blotting using standard techniques (Ausubel et al. 1987) with a probe made by nick-translation of poly/dGdT) (Pharmacia). Yeast genomic DNA $(20 \mu \mathrm{g})$ was incubated in BAL 31 buffer at $30^{\circ} \mathrm{C}$ for $2 \mathrm{hr}$ with or without 0.5 units of BAL 31 enzyme (New England Biolabs) in a volume of $80 \mu$ l. Reactions were stopped by the addition of $16 \mu \mathrm{l}$ of $0.2 \mathrm{M}$ EGTA. DNA was precipitated by adding $50 \mu \mathrm{l}$ of $3.5 \mathrm{M}$ ammonium acetate and $150 \mu \mathrm{l}$ of isopropanol. The DNA pellet was washed twice with $70 \%$ ethanol, resuspended in TE, and digested with Xhol. DNA fragments were resolved on $0.8 \%$ agarose gels and transferred to nitrocellulose for hybridization.

\section{$\beta$-Galactosidase assays}

LexA/RAPl(635-827) and LexA/rapl-12\{635-827) plasmids were cotransformed with a $\mathrm{G}_{\mathrm{AD}} / \mathrm{SIR} 4$ or a pGAD control plasmid into the CTY10-5D two-hybrid reporter strain (a gift of C.-t. Chien and R. Sternglanz, State University of New York, Stony Brook). Transformants were grown in selective media with $0.05 \%$ glucose for $40 \mathrm{hr}$. Five milliliters of cells were pelleted and resuspended in $250 \mu \mathrm{l}$ of $\mathrm{Z}$ buffer $\left(60 \mathrm{~mm} \mathrm{NaH} \mathrm{PO}_{4}, 10 \mathrm{~mm}\right.$ $\mathrm{KCl}, 1 \mathrm{mM} \mathrm{MgSO}, 0.27 \% \beta$-mercaptoethanol) and permeabilized by vortexing $3 \times 1 \mathrm{~min}$ with an equal volume of $0.45-\mathrm{mm}$ glass beads. The supernatants were assayed for protein concentration and $\beta$-galactosidase activity as described previously (Breeden and Nasmyth 1985).

\section{Acknowledgments}

We thank Chris Hardy for useful suggestions and encouragement in the initial stages of this work. We also thank members of the Shore laboratory for helpful comments throughout the course of this study and Katie Freeman and Paolo Moretti, in particular, for sharing unpublished results and materials. We are grateful to David Figurski, Marc Gwadz, and Lorraine Symington for carefully reviewing the manuscript. This work was supported by grants from the National Institutes of Health (NIH) (GM40094), the American Cancer Society (VM-62 and MV-534), and the Irma T. Hirschl Charitable Trust to D.S. S.W.B. was a predoctoral trainee on an NIH Cancer Biology grant (CA09503-0).

The publication costs of this article were defrayed in part by payment of page charges. This article must therefore be hereby 
marked "advertisement" in accordance with 18 USC section 1734 solely to indicate this fact.

\section{References}

Abraham, J., K.A. Nasmyth, J.N. Strathern, A.J.S. Klar, and J.B. Hicks. 1984. Regulation of mating-type information in yeast. J. Mol. Biol. 176: 307-331.

Aparicio, O.M., B.L. Billington, and D.E. Gottschling. 1991. Modifiers of position effect are shared between telomeric and silent mating-type loci in S. cerevisiae. Cell 66: 12791287.

Ausubel, F.M., R. Brent, R.E. Kingston, D.D. Moore, J.G. Seidman, J.A. Smith, and K. Struhl. 1987. Current protocols in molecular biology. John Wiley \& Sons, New York.

Bell, S.P. and B. Stillman. 1992. ATP-dependent recognition of eukaryotic origins of DNA replication by a multiprotein complex. Nature 357: 128-134.

Bell, S.P., R. Kobayashi, and B. Stillman. 1993. Yeast origin recognition complex functions in transcripton silencing and DNA replication. Science 262: 1844-1849.

Brand, A.H., L. Breeden, J. Abraham, R. Sternglanz, and K. Nasmyth. 1985. Characterization of a "silencer" in yeast: A DNA sequence with properties opposite to those of a transcriptional enhancer. Cell 41: 41-48.

Brand, A.H., G. Micklem, and K. Nasmyth. 1987. A yeast silencer contains sequences that can promote autonomous plasmid replication and transcriptional activation. Cell 51: 709-719.

Breeden, L. and K. Nasmyth. 1985. Regulation of the yeast $H O$ gene. Cold Spring Harbor Symp. Quant. Biol. 50: 643-650.

Buchman, A.R., W.J. Kimmerly, J. Rine, and R.D. Kornberg. 1988a. Two DNA-binding factors recognize specific sequences at silencers, upstream activating sequences, autonomously replicating sequences, and telomeres in Saccharomyces cerevisiae. Mol. Cell. Biol. 8: 210-225.

Buchman, A.R., N.F. Lue, and R.D. Kornberg. 1988b. Connections between transcriptional activators, silencers, and telomeres as revealed by functional analysis of a yeast DNAbinding protein. Mol. Cell. Biol. 8: 5086-5099.

Chien, C.-t., P.L. Bartel, R. Sternglanz, and S. Fields. 1991. The two-hybrid system: A method to identify and clone genes for proteins that interact with a protein of interest. Proc. Natl. Acad. Sci. 88: 9578-9582.

Chien, C.-t., S. Buck, R. Sternglanz, and D. Shore. 1993. Targeting of SIRl protein establishes transcriptional silencing at $H M$ loci and telomeres in yeast. Cell 75: 531-541.

Conrad, M.N., J.H. Wright, A.J. Wolf, and V.A. Zakian. 1990. RAPl protein interacts with yeast telomeres in vivo: Overproduction alters telomere structure and decreases chromosome stability. Cell 63: 739-750.

Diffley, J.F. and B. Stillman. 1989. Similarity between the transcriptional silencer binding proteins ABF1 and RAP1. Science 246: 1034-1038.

Diffley, J.F.X. and J.H. Cocker. 1992. Protein-DNA interactions at a yeast replication origin. Nature 357: 169-172.

Feldman, J.B., J.B. Hicks, and J.R. Broach. 1984. Identification of sites required for repression of a silent mating-type locus in yeast. J. Mol. Biol. 178: 815-834.

Foss, M., F.J. McNally, P. Laurenson, and J. Rine. 1993. Origin recognition complex (ORC) in transcriptional silencing and DNA replication in S. cerevisiae. Science 262: 1838-1844.

Gilson, E., M. Roberge, R. Giraldo, D. Rhodes, and S.M. Gasser. 1993. Distortion of the DNA double helix by RAPl at silencers and multiple telomeric binding sites. I. Mol. Biol.
231: 293-310.

Gottschling, D.E., O.M. Aparicio, B.L. Billington, and V.A. Zakian. 1990. Position effect at $S$. cerevisiae telomeres: Reversible repression of pol II transcription. Cell 63: 751-762.

Haber, J.E. and J.P. George. 1979. A mutation that permits the expression of normally silent copies of mating type information in Saccharomyces cerevisiae. Genetics 93: 13-35.

Hardy, C.F.J., D. Balderes, and D. Shore. 1992a. Dissection of a carboxy-terminal region of the yeast regulatory protein RAPl with effects on both transcriptional activation and silencing. Mol. Cell. Biol. 12: 1209-1217.

Hardy, C.F.J., L. Sussel, and D. Shore. 1992b. A RAP1-interacting protein involved in silencing and telomere length regulation. Genes \& Dev. 6: 801-814.

Ivy, J.M., A.J.S. Klar, and J.B. Hicks. 1986. Cloning and characterization of four SIR genes from Saccharomyces cerevisiae. Mol. Cell. Biol. 6: 688-702.

Kimmerly, W., A. Buchman, R. Kornberg, and J. Rine. 1988. Roles of two DNA-binding factors in replication, segregation and transcriptional repression mediated by a yeast silencer. EMBO /. 7: 2241-2253.

Klar, A.J.S., S. Fogel, and K. McLeod. 1979. MAR1-a regulator of $H M a$ and $H M \alpha$ loci in Saccharomyces cerevisiae. Genetics 93: 37-50.

Klar, A.J.S., J.N. Strathern, J.R. Broach, and J.B. Hicks. 1981. Regulation of transcription in expressed and unexpressed mating-type cassettes of yeast. Nature 289: 239-244.

Kurtz, S. and D. Shore. 1991. The RAPl protein activates and silences transcription of mating-type genes in yeast. Genes \& Dev. 5: 616-628.

Kyrion, G., K.A. Boakye, and A.J. Lustig. 1992. C-terminal truncation of RAPl results in the deregulation of telomere size, stability, and function in Saccharomyces cerevisiae. Mol. Cell. Biol. 12: 5159-5173

Kyrion, G., K. Liu, C. Liu, and A.J. Lustig. 1993. RAPl and telomere structure regulate telomere position effects in Saccharomyces cerevisiae. Genes \& Dev. 7: 1146-1159.

Laurenson, P. and J. Rine. 1992. Silencers, silencing, and heritable transcriptional states. Microbiol. Rev. 56: 543-560.

Longtine, M.S., N.M. Wilson, M.E. Petracek, and J. Berman. 1989. A yeast telomere binding activity binds to two related telomere sequence motifs and is indistinguishable from RAP1. Curr. Genet. 16: 225-240.

Lustig, A.J., S. Kurtz, and D. Shore. 1990. Involvement of the silencer and UAS binding protein RAPl in regulation of telomere length. Science 250: 549-553.

Micklem, G., A. Rowley, J. Harwood, K. Nasmyth, and J.F.X. Diffley. 1993. Yeast origin recognition complex is involved in DNA replication and transcriptional silencing. Nature 366: 87-89.

Moretti, P., K. Freeman, L. Coodly, and D. Shore. 1994. Evidence that a complex of SIR proteins interacts with the silencer and telomere-binding protein RAPl. Genes \& Dev. 8: $2257-2269$.

Nasmyth, K.A., K. Tatchell, B.D. Hall, C. Astell, and M. Smith. 1981. A position effect in the control of transcription at yeast mating-type loci. Nature 289: 244-250.

Oliver, S.G., Q.J.M. van der Aart, M.L. Agostoni-Carbone, M. Aigle, L. Alberghina, D. Alexandraki, G. Antione, R. Awar, J.P.G. Ballesta, P. Benit et al. 1992. The complete DNA sequence of yeast chromosome III. Nature 357: 38-46.

Pillus, L. and J. Rine. 1989. Epigenetic inheritance of transcriptional states in S. cerevisiae. Cell 59: 637-647.

Renauld, H., O.M. Aparicio, P.D. Zierath, B.L. Billington, S.K. Chhablani, and D.E. Gottschling. 1993. Silent domains are assembled continuously from the telomere and are defined 
by promoter distance and strength, and by SIR3 dosage. Genes \& Dev. 7: 1133-1145.

Rine, J. and I. Herskowitz. 1987. Four genes responsible for a position effect on expression from HML and HMR in Saccharomyces cerevisiae. Genetics 116: 9-22.

Rine, J., J.N. Strathern, J.B. Hicks, and I. Herskowitz. 1979. A suppressor of mating-type locus mutations in Saccharomyces cerevisiae: Evidence for and identification of cryptic mating type loci. Genetics 93: 877-901.

Rose, M.D., F. Winston, and P. Hieter. 1990. Methods in yeast genetics: A laboratory course manual. Cold Spring Harbor Laboratory Press, Cold Spring Harbor, New York.

Shore, D. and K. Nasmyth. 1987. Purification and cloning of a DNA binding protein from yeast that binds to both silencer and activator elements. Cell 51: 721-732.

Shore, D., M. Squire, and K.A. Nasmyth. 1984. Characterization of two genes required for position effect control of mating type. EMBO J. 3: 2817-2823.

Shore, D., D.J. Stillman, A.H. Brand, and K.A. Nasmyth. 1987. Identification of silencer binding proteins from yeast: Possible roles in SIR control and DNA replication. EMBO $/$. 6: $461-467$.

Sikorski, R. and P. Hieter. 1989. A system of shuttle vectors and yeast host strains designed for efficient manipulation of DNA in Saccharomyces cerevisiae. Genetics 122: 19-27.

Stone, E.M., M.J. Swanson, A.M. Romeo, J.B. Hicks, and R. Sternglanz. 1991. The SIR1 gene of Saccharomyces cerevisiae and its role as an extragenic suppressor of several mating-defective mutants. Mol. Cell. Biol. 11: 2253-2262.

Sussel, L. and D. Shore. 1991. Separation of transcriptional activation and silencing functions of the RAP1-encoded repressor/activator protein 1 : Isolation of viable mutants affecting both silencing and telomere length. Proc. Natl. Acad. Sci. 88: 7749-7753.

Sussel, L., D. Vannier, and D. Shore. 1993. Epigenetic switching of transcriptional states: cis- and trans-acting factors affecting establishment of silencing at the HMR locus in Saccharomyces cerevisiae. Mol. Cell. Biol. 13: 3919-3928.

Vignais, M.-L. and A. Sentenac. 1989. Asymmetric DNA bending induced by the yeast multifunctional factor TUF. J. Biol. Chem. 264: 8463-8466. 


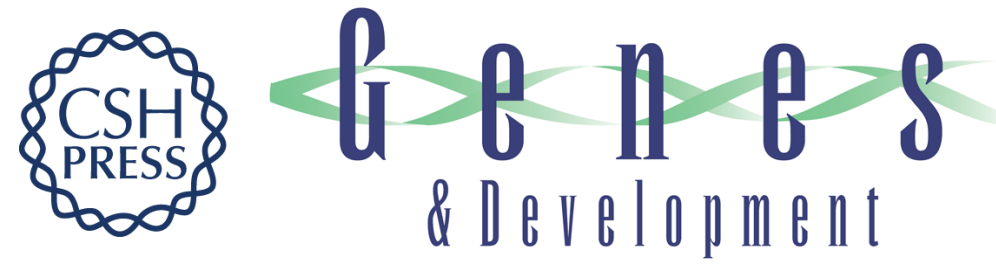

\section{Action of a RAP1 carboxy-terminal silencing domain reveals an underlying competition between HMR and telomeres in yeast.}

S W Buck and D Shore

Genes Dev. 1995, 9:

Access the most recent version at doi:10.1101/gad.9.3.370

References This article cites 47 articles, 25 of which can be accessed free at:

http://genesdev.cshlp.org/content/9/3/370.full.html\#ref-list-1

License

Email Alerting

Service right corner of the article or click here.

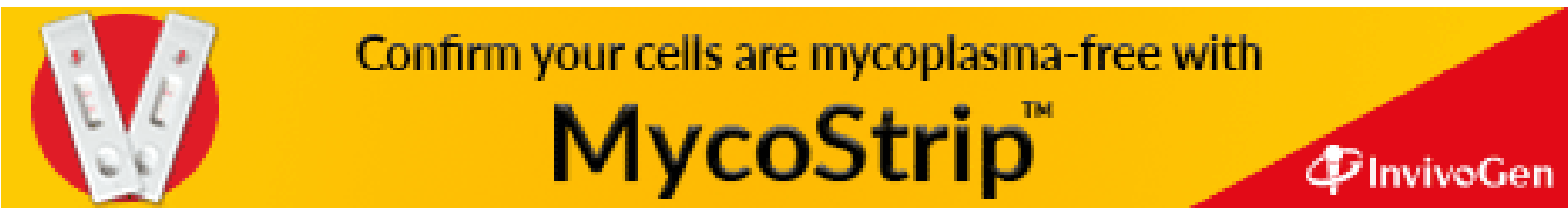

